\title{
Sunset-sunrise difference in solar occultation ozone measurements (SAGE II, HALOE, and ACE-FTS) and its relationship to tidal vertical winds
}

\author{
T. Sakazaki ${ }^{1}$, M. Shiotani ${ }^{1}$, M. Suzuki ${ }^{2}$, D. Kinnison ${ }^{3}$, J. M. Zawodny ${ }^{4}$, M. McHugh ${ }^{5}$, and K. A. Walker ${ }^{6}$ \\ ${ }^{1}$ Research Institute for Sustainable Humanosphere, Kyoto University, Uji, Japan \\ ${ }^{2}$ Institute of Space and Astronautical Science, Japan Aerospace Exploration Agency, Sagamihara, Japan \\ ${ }^{3}$ National Center for Atmospheric Research, Boulder, USA \\ ${ }^{4}$ NASA Langley Research Center, Hampton, USA \\ ${ }^{5}$ Global Atmospheric Technologies and Sciences, Newport News, USA \\ ${ }^{6}$ Department of Physics, University of Toronto, Toronto, Canada \\ Correspondence to: T. Sakazaki (takatoshi_sakazaki@ rish.kyoto-u.ac.jp)
}

Received: 9 May 2014 - Published in Atmos. Chem. Phys. Discuss.: 18 June 2014

Revised: 27 October 2014 - Accepted: 9 December 2014 - Published: 23 January 2015

\begin{abstract}
This paper contains a comprehensive investigation of the sunset-sunrise difference (SSD, i.e., the sunsetminus-sunrise value) of the ozone mixing ratio in the latitude range of $10^{\circ} \mathrm{S}-10^{\circ} \mathrm{N}$. SSD values were determined from solar occultation measurements based on data obtained from the Stratospheric Aerosol and Gas Experiment (SAGE) II, the Halogen Occultation Experiment (HALOE), and the Atmospheric Chemistry Experiment-Fourier transform spectrometer (ACE-FTS). The SSD was negative at altitudes of $20-30 \mathrm{~km}(-0.1 \mathrm{ppmv}$ at $25 \mathrm{~km})$ and positive at $30-50 \mathrm{~km}(+0.2 \mathrm{ppmv}$ at $40-45 \mathrm{~km})$ for HALOE and ACEFTS data. SAGE II data also showed a qualitatively similar result, although the SSD in the upper stratosphere was 2 times larger than those derived from the other data sets. On the basis of an analysis of data from the Superconducting Submillimeter-Wave Limb-Emission Sounder (SMILES) and a nudged chemical transport model (the specified dynamics version of the Whole Atmosphere Community Climate Model: SD-WACCM), we conclude that the SSD can be explained by diurnal variations in the ozone concentration, particularly those caused by vertical transport by the atmospheric tidal winds. All data sets showed significant seasonal variations in the SSD; the SSD in the upper stratosphere is greatest from December through February, while that in the lower stratosphere reaches a maximum twice: during the periods March-April and September-October. Based on an analysis of SD-WACCM results, we found that these
\end{abstract}

seasonal variations follow those associated with the tidal vertical winds.

\section{Introduction}

Stratospheric ozone $\left(\mathrm{O}_{3}\right)$ plays a critical role in the climate system through radiative processes while simultaneously protecting the Earth's surface from harmful ultraviolet radiation. Since the discovery of the ozone hole, longterm changes in ozone concentration have been studied extensively using various ground-based and satellite measurements (WMO, 2011). Useful data sets for long-term monitoring of vertical profiles of ozone levels can be obtained from solar occultation instruments, such as the Stratospheric Aerosol and Gas Experiment (SAGE) II (McCormick, 1987; McCormick et al., 1989), the Halogen Occultation Experiment (HALOE) (Russell et al., 1993), and the Atmospheric Chemistry Experiment-Fourier transform spectrometer (ACE-FTS) (Bernath et al., 2005), as they have measurements that are self-calibrating and have high sensitivity. These measurements have been used to detect seasonal and interannual variability, as well as long-term trends, in the stratospheric ozone concentration (e.g., Shiotani and Hasebe, 1994; Randell and Wu, 1996; Newchurch et al., 2003; WMO 2011; Kyrölä et al., 2013). 
These solar occultation instruments measure the atmosphere at sunrise and sunset (hereafter SR and SS). It has been reported that there is a difference in the observed values between the SR and SS profiles (hereafter this is referred to as the sunset-minus-sunrise difference, SSD). For SAGE II, the SSD is reported to be up to $10 \%$ between altitudes of 35 and $55 \mathrm{~km}$, with a maximum occurring in the tropics (cf. SAGE II version 5.9 data: Wang et al., 1996; version 6.2 data: McLinden et al., 2009; version 7 data: Kyrölä et al., 2013). For HALOE (version 17 data), Brühl et al. (1996) reported an SSD of approximately $5 \%$ in the tropical stratopause. SSD values based on ACE-FTS observations have yet to be reported as far as we know.

A quantification of the SSD and an understanding of the source of this difference are necessary for the construction of combined data sets from SR and SS profiles. As we will explore in this study, the SSD could be caused by any one of three factors, including (1) systematic instrumental/retrieval bias between SR and SS observations, (2) natural diurnal variations, and (3) sampling issues. The factor (3) relates to the fact that if the times of SR and SS measurements are considerably different, the background ozone concentration changes (background changes occur on timescales longer than a day, e.g., in the case of subseasonal variations) during such periods are misinterpreted as an example of SSD (see Sect. 3 for details). In this sense, such spurious contributions, or contamination, should be assessed and removed before discussing the SSD.

In previous studies, the ozone SSD was mainly attributed to factor (1); in other words, factor (2) was thought to be negligible (Wang et al., 1996; Brühl et al., 1996). This was because diurnal variations in stratospheric ozone level were considered to be small and/or to be symmetric between SS and SR if only photochemistry processes are taken into account. However, note that there are few observations of diurnal variations in the stratosphere and thus the above assumption has not been confirmed. In addition, factor (3) may not have been properly considered in some studies (e.g., in the context of interannual variations of the SSD, as shown by Kyrölä et al., 2013; see Sect. 3).

Recently, Sakazaki et al. (2013a; hereafter S13) revealed diurnal variations in ozone concentration from the lower to upper stratosphere using data from both the Superconducting Submillimeter-Wave Limb-Emission Sounder (SMILES) and chemical transport models (CTMs). They showed that the peak-to-peak difference in ozone levels reaches $8 \%$ during a day. An important point here is that, at some altitudes, the diurnal variations exhibit asymmetric ozone levels when comparing measurements at SS and SR, with the SSD reaching around $4 \%$ in the upper stratosphere. S13 showed that the diurnal variations $\left(\left[\mathrm{O}_{3}\right]^{\prime}\right)$ are largely controlled by the following equation:

$$
\frac{\partial\left[\mathrm{O}_{3}\right]^{\prime}}{\partial t}=-w^{\prime} \frac{\partial\left[\overline{\mathrm{O}_{3}}\right]}{\partial z}+S^{\prime}
$$

where $t$ represents time, $w^{\prime}$ the diurnal variations in the vertical winds (tidal vertical winds), $z$ altitude, $\left[\overline{\mathrm{O}_{3}}\right]$ the daily, zonal mean ozone, and $S^{\prime}$ the diurnal variations in chemical production or loss. The first term on the right-hand side denotes the dynamical variation due to vertical transport by atmospheric tidal winds, while the second term denotes the photochemical variation. It should be noted that the dynamical variation results in a maximum at 18:00-20:00 local time (LT) in the upper stratosphere (and at 00:00-06:00 LT in the lower stratosphere; cf. Fig. 7d of S13), possibly causing a positive (negative) SSD. In contrast, although the photochemical variations are also important above an altitude of $30 \mathrm{~km}$ during the daytime, they are almost zero at SR-SS (see Fig. 7b of S13) and so do not contribute to the SSD. This has already been demonstrated and discussed in previous studies (e.g., Pallister and Tuck, 1984; Wang et al., 1996; Brühl et al., 1996). For the tropical mesosphere and lower thermosphere, Marsh and Russell (2000) used HALOE data to attribute the SSD of nitric oxide (NO) to diurnal variations caused by tidal vertical transport.

With regard to tides, the diurnal migrating tide (i.e., the diurnal harmonic component, which depends only on the LT of a particular latitude band and not on longitude) is basically dominant over other higher-order harmonics in the tropical stratosphere. Vertical winds associated with the diurnal migrating tide become maximal in the tropics, so that diurnal variations in ozone levels caused by vertical transport also reach a maximum in the tropics (see Fig. 8 of S13). In the tropical stratosphere, the diurnal migrating tide is known to exhibit a significant seasonal dependence, with its amplitude reaching a peak in January-February and July-September, as seen in satellite-based temperature measurements (e.g., Wu et al., 1998; Zeng et al., 2008; Huang et al., 2010; Sakazaki et al., 2012). These findings suggest that the tidal vertical winds and, consequently, the SSD also show similar seasonal variations. Note that the tidal vertical wind is relatively difficult to observe directly because of its rather small amplitude. We suggest that in the presence of vertical gradient of ozone, the SSD pertaining to the ozone levels could be used to obtain quasi-observational evidence of tidal vertical winds in the tropical stratosphere.

As outlined above, SSDs have been noticed but they were considered independently for each occultation instrument. In addition, they have not been investigated fully in terms of diurnal ozone variations. The purpose of this study is first to quantify the SSD, including its seasonal dependence, by analyzing and comparing data from three independent solar occultation instruments: SAGE II, HALOE, and ACE-FTS. The differences among the data sets due to differences in measurement times are discussed with the aid of CTM data (from the specified dynamics version of the Whole Atmosphere Community Climate Model: SD-WACCM), which provide a homogeneous data set covering the full operational periods of each of the three satellite missions. Next, we interpret the SSD in terms of diurnal variations based on SMILES 
measurements and 3-hourly, 3-D-gridded SD-WACCM data, which provide data not only at SR-SS but also for the full diurnal cycle. The 3-D-gridded SD-WACCM data are also used to discuss diurnal variations related to vertical transport and photochemistry. This study focuses on the tropical stratosphere at latitudes of $10^{\circ} \mathrm{S}-10^{\circ} \mathrm{N}$ between 20 and $60 \mathrm{~km}$ in altitude because the SSD is greatest in the tropics. The remainder of this article is organized as follows: Sects. 2 and 3 describe the data sets and analysis methods, respectively. Section 4 describes the SSD and its seasonal variations, and we also discuss the contribution from diurnal ozone variations. Section 5 summarizes our main results.

\section{Data description}

In this study, the average SSD in the tropical stratosphere within the latitude range $10^{\circ} \mathrm{S}-10^{\circ} \mathrm{N}$ is analyzed and discussed using data from three solar occultation instruments: SAGE II, HALOE, and ACE-FTS. To quantify the SSD caused by natural diurnal variations in ozone concentration, data from SMILES limb emission measurements are also analyzed. In addition, two data sets from SD-WACCM are used: the satellite coincidence data subset and the full 3hourly, 3-D-gridded data. The former is used to discuss the difference in SSD among the different satellite data sets, while the latter is used to consider the SSD in terms of diurnal variations. All data are analyzed at geometric altitudes in the stratosphere between 20 and $60 \mathrm{~km}$.

Note that there is no systematic difference in the tracking procedure between SR and SS. SAGE II tracks the Sun by moving the field of view (FOV) across the solar disk. As the FOV went off the edge of the Sun, the scan mirror reverses direction. HALOE tracks the top edge of the Sun, with the science FOV held a fixed angle below this. Extensive SRSS comparisons have been carried out over the 14-year measurement record and no significant bias in tracking is perceivable. The ACE-FTS is aligned by a tracking system that keeps it pointed at the radiometric center of the Sun. While there might exist a very small difference between SR and SS tracking, this has been examined carefully and no significant SR-SS bias exists. Further details are provided in the following subsections.

\subsection{SAGE II}

The SAGE mission has deployed three instruments, i.e., SAGE I, II, and III. This study uses data from SAGE II because these measurements cover the longest period. SAGE II was launched in October 1984 on board the Earth Radiation Budget Satellite (ERBS) and remained operational until August 2005, providing data for over 21 years. The ERBS operated in a $610 \mathrm{~km}$ altitude, circular orbit with an inclination of $56^{\circ}$. SAGE II is a seven-channel spectrometer capable

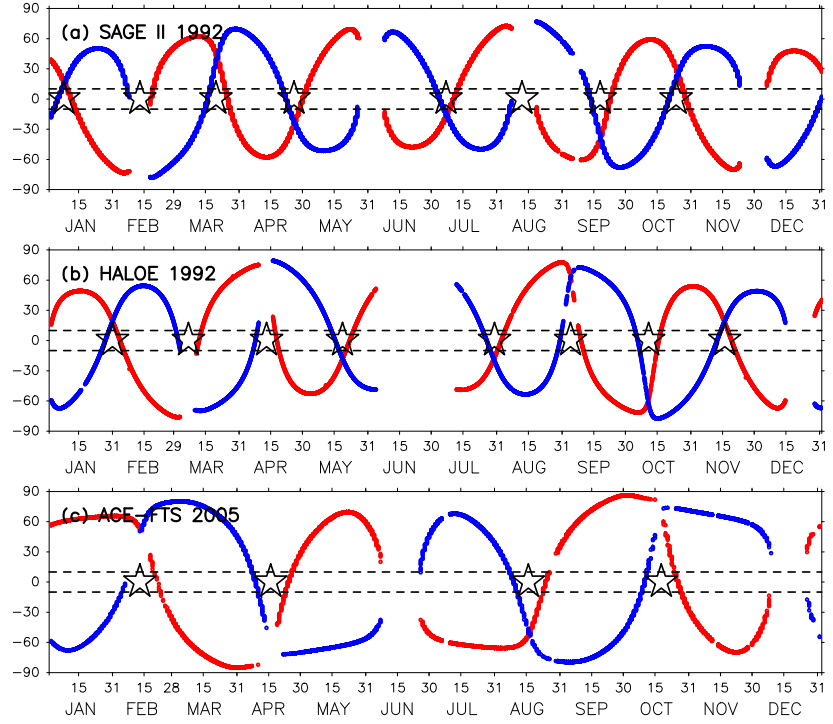

Figure 1. Measurement tracks of (a) SAGE II in 1992, (b) HALOE in 1992, and (c) ACE-FTS in 2005. Red and blue closed circles show SR and SS measurements, respectively. Open stars indicate $\mathrm{SR}-\mathrm{SS}$ measurement pairs. Dashed lines denote $10^{\circ} \mathrm{S} / \mathrm{N}$.

of obtaining ozone levels from measurements in the $600 \mathrm{~nm}$ Chappuis band (McCormick et al., 1987, 1989).

Figure 1a shows the SAGE II measurement locations obtained in 1992 . The latitude coverage ranges from $80^{\circ} \mathrm{S}$ to $80^{\circ} \mathrm{N}$. SAGE II performed two occultation measurements per orbit, sampling two narrow latitude regions each day. As a result, for each day up to 15 SR and 15 SS profiles were obtained near the same latitude regions but spaced some $24^{\circ}$ apart in longitude. Approximately 10 times per year, the tracks of the SR and SS measurements crossed over. The sampling pattern (i.e., the measurement day of the year at a particular latitude) changed gradually from year to year and so covers the whole year when data are collected for several years.

We analyzed SAGE II version 7 data (Damaedo et al., 2013) obtained during the period 1985-2005. Data were provided for geometric altitudes between 0 and $70 \mathrm{~km}$ at intervals of $0.5 \mathrm{~km}$. Geometric altitudes were determined by the viewing geometry with the aid of data from the ModernEra Retrospective Analysis for Research and Applications (MERRA) reanalysis (Rienecker et al., 2011). The uncertainty in altitude registration is less than $20 \mathrm{~m}$ (Damaedo et al., 2013). Ozone mixing ratio is calculated as the ratio of ozone number density to atmospheric density, both of which are provided in SAGE II data. The atmospheric density is not measured by SAGE II but derived from MERRA data; however, the results of SSD (\%) (cf. Fig. 5b) do not change even if the following analysis is done based on ozone number density. Prior to our detailed analysis, data were screened following the guidelines provided in the SAGE II version 7 readme file (https://eosweb.larc.nasa.gov/project/ 
sage2/sage2_release_v7_notes) as follows. Any profile with an error estimate larger than $10 \%$ at altitudes between 30 and $50 \mathrm{~km}$ was rejected. Data points with an uncertainty estimate of $300 \%$ or greater were rejected. Data points at the altitude of and below the occurrence of an aerosol extinction value greater than $0.006 \mathrm{~km}^{-1}$ were rejected. Data points at the altitude of and below the occurrence of both the $525 \mathrm{~nm}$ aerosol extinction value exceeding $0.001 \mathrm{~km}^{-1}$ and the $525 / 1020 \mathrm{ex}-$ tinction ratio of less than 1.4 were rejected. Data points pertaining to altitudes below $35 \mathrm{~km}$ with an uncertainty estimate of $200 \%$ (or larger) were rejected. On the basis of this screening process, $3.9 \%$ and $5.6 \%$ of all profiles were rejected for the times of SR and SS, respectively.

\subsection{HALOE}

HALOE was launched in September 1991 on board the Upper Atmosphere Research Satellite (UARS) and remained operational until November 2005, providing data over 15 years. UARS was placed in a $585 \mathrm{~km}$ circular orbit with an inclination of $57^{\circ}$ (Russell et al., 1993). Its ozone measurements were made at mid-infrared (mid-IR) wavelengths $(9.6 \mu \mathrm{m})$.

The HALOE measurement locations during 1992 are shown in Fig. 1b. The latitude coverage was approximately $80^{\circ} \mathrm{S}-80^{\circ} \mathrm{N}$. The instruments measured up to $15 \mathrm{SR}$ and 15 SS profiles each day. Approximately 10 times per year, the tracks of the SR and SS measurements crossed over. As with SAGE II, the sampling pattern of HALOE changed gradually from year to year.

We analyzed HALOE version 19 data obtained over the period 1991-2005 (e.g., Randall et al., 2003). Data were provided at 271 pressure levels, i.e., $1000 \times 10^{-(i-1) / 30} \mathrm{hPa}$ $(i=1,2, \ldots, 271)$, between 1000 and $10^{-6} \mathrm{hPa}$, with a corresponding vertical spacing of approximately $0.5 \mathrm{~km}$. Geometric altitudes were also provided in relation to the pressure levels for each profile so that we mapped ozone mixing ratio data onto geometric altitude levels between 0 and $70 \mathrm{~km}$, with a spacing of $0.5 \mathrm{~km}$. No screening was performed on the HALOE data.

HALOE profiles are registered in altitude in an iterative fashion, and the resulting registration is generally assessed to be better than $100 \mathrm{~m}$ (McHugh et al., 2003, 2005). Initially, the data are placed on an altitude grid based on the HALOE measurements versus zenith angle. A first pressure registration is performed using the measured transmittance profile from the $2.8 \mu \mathrm{m}$ channel (dominated by $\mathrm{CO}_{2}$ absorption). In this process, the altitude grid is shifted to best match simulated transmittances in the 30 to $45 \mathrm{~km}$ altitude range, assuming the temperature profile from the National Center for Environmental Prediction (NCEP) reanalysis (Beaver et al., 1994; Remsberg et al., 2002; see Kalnay et al., 1996 for NCEP reanalysis). Temperatures and corresponding hydrostatic pressures are then retrieved in an iterative upward fashion from $30 \mathrm{~km}$ at $1.5 \mathrm{~km}$ spacing. Finally the retrieved
$\mathrm{T}(\mathrm{p})$ profile is merged into the NCEP profile from 34 (pure NCEP) to $43 \mathrm{~km}$ (pure HALOE retrieval). Pressures are calculated assuming hydrostatic balance. This entire process is repeated again after retrieval of water vapor and finally after a retrieval of aerosols to account for all significant interfering absorption in the $2.8 \mu \mathrm{m} \mathrm{CO} \mathrm{CO}_{2}$ channel.

\subsection{ACE-FTS}

ACE-FTS was launched in August 2003 on board the SCISAT-1 satellite. SCISAT-1 is operating in a circular, lowEarth orbit, with a $74^{\circ}$ inclination and an altitude of $650 \mathrm{~km}$ (Bernath et al., 2005). ACE-FTS measures ozone at IR wavelengths $(9.6 \mu \mathrm{m})$.

Figure 1c shows the ACE-FTS measurement locations during 2005 . The latitude coverage is approximately $85^{\circ} \mathrm{S}-$ $85^{\circ} \mathrm{N}$. The instruments measure up to $15 \mathrm{SR}$ and $15 \mathrm{SS}$ profiles each day. Approximately six times per year, the tracks of the SR and SS measurements cross over. Unlike SAGE II and HALOE, however, the sampling pattern changes little from year to year. Thus, data for $10^{\circ} \mathrm{S}-10^{\circ} \mathrm{N}$ are obtained only in February, April, August, and October of each year (see Fig. 1c).

We analyzed the most recent data, version 3 (Dupuy et al., 2009; Waymark et al., 2013), obtained between 2004 and 2011. Data were provided at geometric altitudes from 0 to $140 \mathrm{~km}$, with a spacing of $1 \mathrm{~km}$. Some of the data obtained during this period had measurement problems and were not used based on the recommendations from the ACE-FTS data issues list (https://databace.scisat.ca/validation/data_issues. php).

Altitudes in ACE-FTS measurements are defined as follows (see Boone et al., 2005 for details). At low altitudes (below $\sim 42 \mathrm{~km}$ ), pointing information from the satellite is relatively poor and the pointing is quite variable, with refraction effects plus clouds and aerosols affecting the instrument's pointing. Therefore, geometry is derived through analysis of the ACE-FTS spectra. $\mathrm{CO}_{2}$ volume mixing ratio is fixed to its "known" profile, and then $\mathrm{CO}_{2}$ lines are analyzed to determine pressure and temperature. Hydrostatic equilibrium is used to express the altitude separations between measurements in terms of pressure and temperature during the retrieval, so geometry is determined simultaneously. At high altitudes (above 60-65 km), geometry is relatively well known from first principles (i.e., given the knowledge of the location of the satellite and the look direction to the Sun at a given time, one can calculate the pointing information). In the middle $(42-60 \mathrm{~km}), \mathrm{CO}_{2}$ VMR is still "known" and geometry is known. This region allows us to determine the pressure at the "crossover" point (near $42 \mathrm{~km}$ ) to be used in the calculation of altitude at low altitudes (below $\sim 43 \mathrm{~km}$ ) via hydrostatic equilibrium. A final altitude registration is performed using the Canadian Meteorological Centre model output at the lowest altitudes $(\sim 15-25 \mathrm{~km})$. The uncertainty on altitude registration for the ACE-FTS is $150 \mathrm{~m}$. 


\subsection{SMILES}

SMILES was attached to the Japanese Experiment Module (JEM) on board the International Space Station (ISS) through the cooperation of the Japan Aerospace Exploration Agency (JAXA) and the National Institute of Information and Communications Technology (NICT). The ISS is in a circular orbit at a typical altitude between 350 and $400 \mathrm{~km}$, with an inclination of $51.6^{\circ}$. Its latitude coverage is $38^{\circ} \mathrm{S}-65^{\circ} \mathrm{N}$. SMILES measured the Earth's limb and made global observations of the minor constituents in the middle atmosphere in the $600 \mathrm{GHz}$ range between 12 October 2009 and 21 April 2010 (Kikuchi et al., 2010). Unlike the solar occultation measurements (SAGE II, HALOE, and ACE-FTS), limb emission measurements are made continuously following the orbit track, not only at SR and SS but also throughout the day and night. As a result, two data sets for ascending and descending nodes are obtained every day in each latitude band. In addition, the ISS is not in a Sun-synchronous orbit, and its orbital plane rotates every 60 days; consequently, a full diurnal cycle in the tropics is covered in 30 days by the ascending/descending nodes.

For SMILES, we defined the SS and SR profiles as those characterized by solar zenith angles between 80 and $100^{\circ}$. Note, again, that SMILES measurements cover the full diurnal cycle as well as during SS and SR. Thus, the SSD related to diurnal variations in ozone level can be calculated. With regard to the quality of ozone data from SMILES, Imai et al. (2013a) compared the ozone concentration profiles from the SMILES version 2.1 data set with those from five satellite measurements and two CTMs (including SD-WACCM), and found that in the stratosphere the agreement was generally better than $10 \%$. Imai et al. (2013b) compared the ozone concentrations profiles from the SMILES version 2.3 data set with those from worldwide ozonesonde stations and found that the agreement was between 6 and $15 \%$ for $20-26 \mathrm{~km}$ at low latitudes; part of this difference was attributed to issues related to the ozonesonde measurement system.

In this study, version 2.4 data were analyzed (JEM/SMILES L2 Products Guide for version 2.4: http: //smiles.tksc.jaxa.jp/12data/pdf/L2dataGuide_130703.pdf).

Data were provided at geometric altitudes between 8 and $118 \mathrm{~km}$ with a vertical spacing of $2 \mathrm{~km}$ (below $58 \mathrm{~km}$ ) or $3 \mathrm{~km}$ (above $58 \mathrm{~km}$ ). By updating the screening conditions, the number of retrieved profiles in version 2.4 was significantly larger than that in version 2 . We did not find any significant differences in diurnal variation between versions 2.4 and 2 (which was used by S13). For stratospheric diurnal variations in the SMILES data, Parrish et al. (2013) found good agreement with the results from ground-based microwave measurements at Mauna Loa $\left(19.5^{\circ} \mathrm{N}, 204.5^{\circ} \mathrm{E}\right)$, as well as those from the Microwave Limb Sounder onboard the UARS and Aura satellites.

SMILES does not measure geometric altitude, so that temperature (from SMILES below $\sim 40 \mathrm{~km}$ and from SD-
WACCM above $\sim 40 \mathrm{~km}$ for version 2.4 ) and pressure (from SMILES) are used to calculate the "relative" altitudes from some pressure level with the hydrostatic equilibrium assumption. For deriving the "absolute" altitude, pressure at $30 \mathrm{~km}$ from SD-WACCM output is used (for version 2.4) (C. Mitsuda, personal communication). The uncertainty in altitude registration for SMILES is considered to be in the same order as that for other data sets. Note that there is no systematic difference in the altitude registration between SR and SS.

\subsection{SD-WACCM}

The NCAR WACCM version 4 (WACCM4) is a comprehensive numerical model spanning the range of altitude from the Earth's surface to the thermosphere (Garcia et al., 2007; Kinnison et al., 2007; Marsh et al., 2013). WACCM4 is based on the framework of the NCAR Community Atmosphere Model version 4 (CAM4) and includes all of the physical parameterizations of CAM4 (Neale et al., 2013) and a finite volume dynamical core (Lin, 2004) for the tracer advection. A version of WACCM4 has been developed that allows the model to be run with specified (external) meteorological fields (Kunz et al., 2011). Here SD-WACCM is a CTM that nudges WACCM4 temperature, horizontal winds, and surface pressure towards 6-hourly time series from MERRA reanalysis (Rienecker et al., 2011) below $50 \mathrm{~km}$. The CTM data were constrained by meteorological conditions with an hourly timescale so that they could be directly compared with our observational data. Note that the stratospheric ozone concentration and its diurnal variations in the SD-WACCM data have been analyzed and that the results agreed well with those based on the SMILES data (Imai et al., 2013a; S13).

The horizontal resolution used was $2.5^{\circ}$ in longitude and $1.9^{\circ}$ in latitude, and the model time step was $30 \mathrm{~min}$. We prepared and analyzed a satellite coincidence data subset, which was sampled at the nearest time and grid point to each satellite measurement. The measurement longitude, latitude, and time were used pertaining to an altitude of $30 \mathrm{~km}$. In other words, we did not consider any altitude dependence of the longitude, latitude, or time for a given profile. This may cause estimation errors in the mesosphere where the ozone concentration changes rapidly at SR and SS (e.g., S13). Data were provided at 88 pressure levels and mapped onto geometric altitude grids corresponding to those of the satellite data sets. The geometric altitude $(z)$ is calculated from geopotential height $(Z)$ by the equation 
$z=\frac{r Z}{\frac{g}{g_{0}} r-Z}$

where $g$ is the gravity at $(z, \phi), g_{0}\left(=9.80665 \mathrm{~m} \mathrm{~s}^{-2}\right)$ is the reference gravity, and $r$ is the radius of the Earth (cf. Mahoney, 2008, available from the web site http://mtp. mjmahoney.net/www/notes/pt_accuracy/ptaccuracy.html).

As well as the satellite coincidence data set (only at SR and SS), we analyzed 3-hourly, 3-D-gridded data obtained between 2008 and 2010 (hereafter referred to as the "fullgrid" data) to extract the full diurnal cycle. We only used data for these 3 years because of constraints on data storage. As well as ozone mixing ratio, vertical wind in geometric altitude $(w)$ and chemical generation or loss $(S)$ in SD-WACCM data were also analyzed to assess the dynamical and photochemical contributions to the SSD (cf. Eq. 1). On pressure levels, $w$ was calculated on pressure levels from geometric altitude $(z)$ and vertical velocity $(\omega)$ by using the formula

$w=\frac{D z}{D t}=\frac{\partial z}{\partial t}+u \cdot \nabla z+\rho g \omega$,

where $\boldsymbol{u}$ is horizontal wind, $\rho$ is density, and $g$ is gravity acceleration; then, the calculated $w$ was mapped onto geometric altitude grids.

\section{Analysis methods}

When calculating the SSD, careful consideration should be given to the sampling issues. Figure 2 shows the number of $\mathrm{SR}$ (red) and SS (blue) profiles in the latitude range of $10^{\circ} \mathrm{S}-$ $10^{\circ} \mathrm{N}$ obtained during the observation period. We see that the SR and SS profiles are not distributed evenly; e.g., there are no SR (SS) profiles from November to January (May to July) between 2001 and 2005 for SAGE II. This indicates that if the SSD is calculated by simply averaging all SR and SS profiles for a certain period (e.g., Kyrölä et al., 2013), it could be significantly contaminated by seasonal/interannual variations in ozone concentrations. In fact, Kyrölä et al. (2013) reported that the SSD profile for 2001-2005 was considerably different to those recorded in the other periods (1985-1990, 1991-1995, and 1996-2000); we attribute this to contamination caused by uneven sampling during this period. To resolve this issue, we calculated the SSD in SR-SS pairs that have both SR and SS profiles measured at almost the same time (see the open stars in Fig. 1). A pair is defined such that it has more than one profile for both SR and SS within 15 days (30 days) for SAGE II and HALOE (ACE-FTS). However, note that there is still a difference of 10-15 days in the SR and SS measurement times for each pair. We found that changes in ozone levels during these 10-15 days also contaminate the SSD. Therefore, this effect was further assessed and removed (see below).

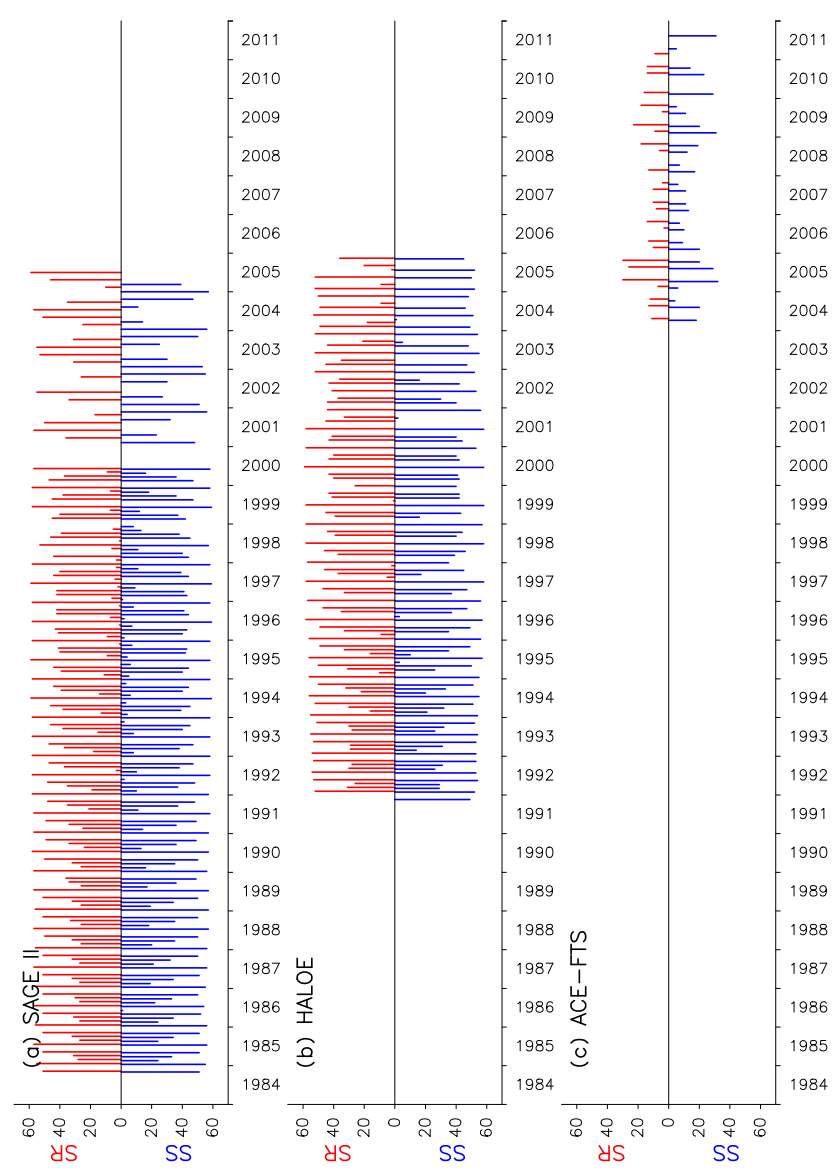

Figure 2. Number of profiles obtained for observations at $10^{\circ} \mathrm{S}-$ $10^{\circ} \mathrm{N}$ from (a) SAGE II, (b) HALOE, and (c) ACE-FTS. Red and blue bars show the number of SR and SS profiles, respectively.

Approximately eight pairs for both SAGE II and HALOE and four pairs for ACE-FTS were defined for each year (see Fig. 1). The differences in measurement days between SR and SS profiles were less than about 10 days (15 days) for SAGE II and HALOE (ACE-FTS). The total number of pairs for the entire period was 128 for SAGE II, 86 for HALOE, and 25 for ACE-FTS. There were no SR-SS pairs for SAGE II data after 2001 although the measurements continued until 2005. Also, for ACE-FTS, SR-SS pairs are defined only in February, April, August, and October. Between 10 and 50 profiles were obtained for SR and SS in each pair (see Fig. 2).

Figure 3 shows the time series of the ozone mixing ratio at an altitude of $40 \mathrm{~km}\left(10^{\circ} \mathrm{S}-10^{\circ} \mathrm{N}\right)$ based on HALOE data for the period 1992-1993. The mean profile for each SR and SS for the $i$ th SR-SS pair $\left(\mathrm{SR}^{i}\right.$ and $\left.\mathrm{SS}^{i}\right)$ was produced by averaging the SR (red open circles) and SS (blue open circles) data, respectively. Subsequently, for each pair the original SSD $\left(\mathrm{SSD}_{\mathrm{org}}^{i}\right)$ was calculated as the difference between the mean SS and SR profiles (i.e., $\mathrm{SSD}_{\mathrm{org}}^{i}=\mathrm{SS}^{i}-\mathrm{SR}^{i}$ ). Figure 4 shows individual $\mathrm{SSD}_{\mathrm{org}}^{i}$ values averaged at altitudes of $40-45 \mathrm{~km}$ based on HALOE data and sorted by time of year 


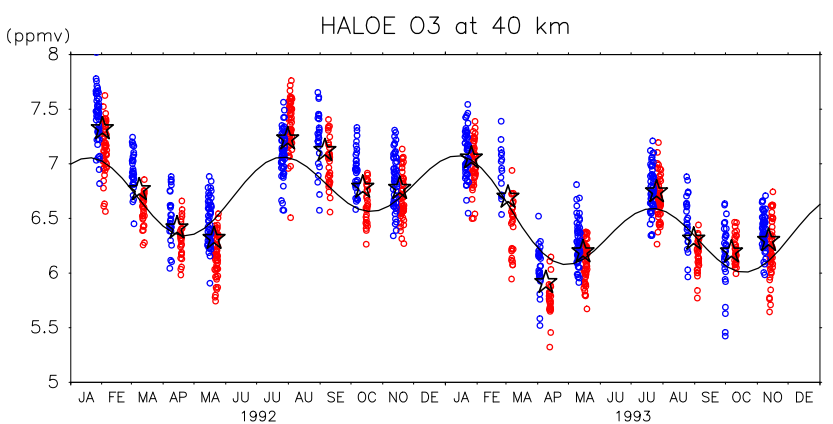

Figure 3. Time series of the ozone mixing ratio observed by HALOE during the period 1992-1993 at an altitude of $40 \mathrm{~km}$ (between $10^{\circ} \mathrm{S}$ and $10^{\circ} \mathrm{N}$ ). Red and blue open circles show individual measurements at SR and SS, respectively. Open stars denote the average values of SR and SS for each SR-SS pair. The solid curve shows the best-fit function for the average values (see Eq. 4).

(black closed circles). We note again that, although the differences in measurement days between the SR and SS profiles are less than 10-15 days, seasonal variations still produced significant differences during this period and contaminate the SSD. In fact, this effect is not negligible in the stratosphere, where semiannual variations in ozone concentration associated with the stratospheric semiannual oscillation (SAO) exist (e.g., Ray et al., 1994). Thus, we attempted to further remove the contamination caused by seasonal variations, as follows.

For both SAGE II and HALOE we assessed the background ozone concentration changes $\left(\mathrm{O}_{3 \_} \mathrm{BG}\right)$ at each altitude using linear multivariable regression:

$$
\begin{aligned}
& \mathrm{O}_{3 \_\mathrm{BG}}=b+a t+q_{1} \mathrm{QBO}_{10}(t)+q_{2} \mathrm{QBO}_{30}(t) \\
& +\sum_{n=1}^{2}\left(c_{\mathrm{n}} \cos (n \omega t)+s_{\mathrm{n}} \sin (n \omega t)\right)
\end{aligned}
$$

where $t$ is expressed in days, $\mathrm{QBO}_{10}(t)$ and $\mathrm{QBO}_{30}(t)$ are the quasi-biennial oscillation (QBO) indices defined by monthly zonal winds at 10 and $30 \mathrm{hPa}$, respectively, at Singapore (Naujokat, 1986), and $\omega=2 \pi / 365.25\left(\mathrm{rad} \mathrm{day}^{-1}\right)$. The QBO indices are used after normalization by one standard deviation and application of a 12-month running mean (e.g., Gebhardt et al., 2013). For the regression, least-squares fitting was applied to the time series of the average of the SR and $\mathrm{SS}$ in each pair (i.e., $\left(\mathrm{SR}^{i}+\mathrm{SS}^{i}\right) / 2$, the time series of open stars in Fig. 3). The resulting $\mathrm{O}_{3 \_}$BG is also shown in Fig. 3 (solid curve). We see that $\mathrm{O}_{3 \_} \mathrm{BG}$ changes by approximately 0.1 ppmv over 10 days, which is comparable with the SSD (see below and Fig. 4).

The SSD caused by seasonal variation for the $i$ th pair $\left(\mathrm{SSD}_{\text {seas }}^{i}\right)$ was then evaluated as

$\mathrm{SSD}_{\text {seas }}^{i}=\mathrm{O}_{3 \_\mathrm{BG}}\left(t_{\mathrm{SS}}^{i}\right)-\mathrm{O}_{3 \_\mathrm{BG}}\left(t_{\mathrm{SR}}^{i}\right)$,

where $t_{\mathrm{SS}}^{i}$ and $t_{\mathrm{SR}}^{i}$ are the day of $i$ th SS and SR, respectively. Figure 4 also shows $\mathrm{SSD}_{\text {seas }}^{i}$ (blue closed circles). $\mathrm{SSD}_{\text {seas }}^{i}$ ex-

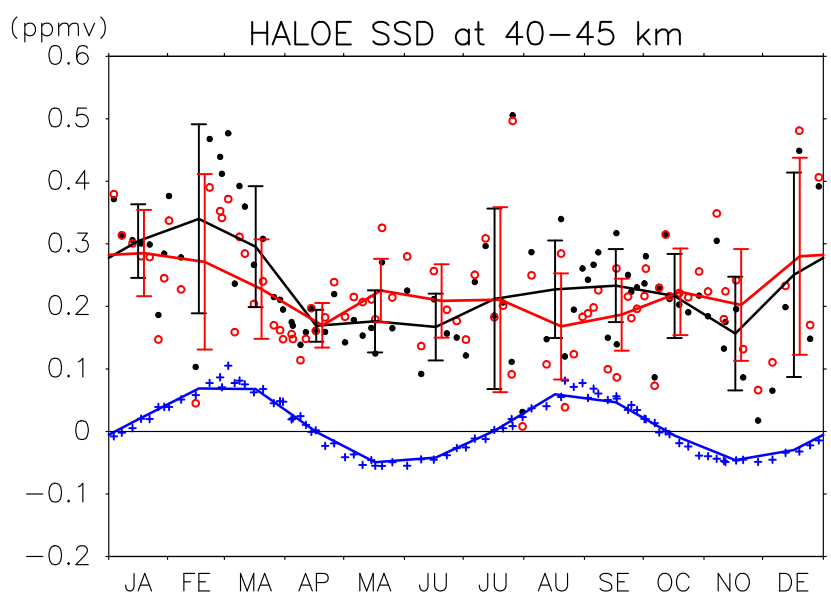

Figure 4. $\mathrm{SSD}_{\text {org }}^{i}$ (black closed circles), $\mathrm{SSD}_{\text {seas }}^{i}$ (blue crosses), and $\mathrm{SSD}_{\mathrm{cor}}^{i}$ (red open circles) averaged at an altitude of $40-45 \mathrm{~km}$ for individual SR-SS pairs sorted by time of year, derived from HALOE data during the period 1990-2005. Black, blue, and red curves denote monthly averaged $\mathrm{SSD}_{\mathrm{org}}, \mathrm{SSD}_{\text {seas }}$, and $\mathrm{SSD}_{\mathrm{org}}$, respectively. Vertical bars show one standard deviation for the monthly SSD $_{\text {org }}$ and $\mathrm{SSD}_{\mathrm{org}}$.

hibits semiannual variations that follow the ozone SAO, with an amplitude of up to $0.1 \mathrm{ppmv}$ at this altitude. Finally, the corrected SSD (SSD $i$ cor ; red open circles in Fig. 4) was calculated as

$\mathrm{SSD}_{\mathrm{cor}}^{i}=\mathrm{SSD}_{\mathrm{org}}^{i}-\mathrm{SSD}_{\text {seas }}^{i}$

We expect that this SSD was only caused by diurnal variations and/or instrumental/retrieval bias.

For ACE-FTS, only four pairs were obtained during the months of interest every year because of the repeating orbit pattern. This leads to incorrect assessment of the seasonal variations (particularly of the SAO) by the above fitting procedure (not shown). Thus, the SSD for ACE ( $\mathrm{SSD}_{\mathrm{cor}}^{i}$ ) was calculated using $\mathrm{SSD}_{\mathrm{org}}^{i}$ from ACE-FTS data and $\mathrm{SSD}_{\text {seas }}^{i}$ from HALOE data. That is, $\mathrm{SSD}_{\text {seas }}^{i}$ is calculated for 2004 2011 using the fitting coefficients estimated from HALOE data during the period of 1990-2005.

Having calculated the SSD for each SR-SS pair, the $\mathrm{SSD}_{\text {cor }}^{i}$ was binned and averaged using monthly bins. For example, if the day of a SR-SS pair was 13 April, the relevant $\mathrm{SSD}_{\text {cor }}^{i}$ was assigned to the April bin. Figure 4 shows the monthly average values of $\operatorname{SSD}_{\text {cor }}^{i}$ as well as those of $\mathrm{SSD}_{\mathrm{org}}^{i}$ and $\mathrm{SSD}_{\text {seas. }}^{i}$. If $\mathrm{SSD}_{\text {org }}$ was used for the analysis (see the black curve), it shows a semiannual variation with maxima in February and July/August/September; however, this is partially the result of contamination from $\mathrm{SSD}_{\text {seas }}$, which shows a semiannual variation (ca. $0.1 \mathrm{ppmv}$ ) associated with the stratospheric SAO (see the blue curve; Ray et al., 1994). When this contamination is removed, as is done in the present study, $\mathrm{SSD}_{\text {cor }}$ instead shows an annual variation with a max- 
imum between December and February (see the red curve). This seasonal variation is discussed in Sect. 4.2.

Finally, the annual mean SSD was calculated as the average of the monthly mean $\mathrm{SSD}_{\text {cor }}$. Note that correction for $\mathrm{SSD}_{\text {seas }}$ is important in the context of the annual mean SSD as well. For SAGE II and HALOE, whose measurements cover the entire year, the annual mean of $\mathrm{SSD}_{\text {cor }}$ is nearly the same as that of $\mathrm{SSD}_{\text {org }}$ because the annual mean of $\mathrm{SSD}_{\text {seas }}$ should be zero. This is, however, not the case for ACE-FTS, which made tropical measurements only in particular months (i.e., February, April, August, and October). In this case, the annual mean of $\mathrm{SSD}_{\text {seas }}$ is not zero but reaches a maximum of approximately $0.1 \mathrm{ppmv}$; thus, the annual mean of $\mathrm{SSD}_{\text {org }}$ is not equal to that of $\mathrm{SSD}_{\text {cor }}$ (not shown).

For SMILES, two kinds of SSDs are calculated with different procedures. The first kind of SSD is based on SR-SS pairs. SR-SS pairs that had more than 10 profiles for both SR and SS were analyzed, and four SR-SS pairs met this requirement (3 November 2009, 31 December 2009, 29 January 2010, and 29 March 2010). Each pair had more than 200 profiles for both SR and SS. In all cases, SR and SS measurements were taken about 5 days apart. Unlike the solar occultation measurements, SMILES observed the $10^{\circ} \mathrm{S}-10^{\circ} \mathrm{N}$ region almost continuously (see Sect. 2.4). Consequently, the changes in background ozone concentration, i.e., $\mathrm{O}_{3}$ BG in Eq. (4), were defined as the time series of ozone concentration over the region $10^{\circ} \mathrm{S}-10^{\circ} \mathrm{N}$ to which a 5 -day running mean was applied. Then $\mathrm{SSD}_{\text {seas }}$ was assessed using Eq. (5) and $\mathrm{SSD}_{\text {cor }}$ was obtained from Eq. (6). The average of the four $\mathrm{SSD}_{\mathrm{cor}} \mathrm{S}$ will be used in Sect. 4.1, while the individual $\mathrm{SSD}_{\mathrm{cor}} \mathrm{S}$ are used in Sect. 4.2 in the context of a discussion of their seasonal dependence. Next, the second kind of SSD is the SSD caused by diurnal variations. This quantity is the difference in ozone levels between 18:00 LT (for SS) and 06:00 LT (for SR), as derived from hourly diurnal ozone-concentration variations in the SMILES data averaged over the period of operation (October 2009-April 2010). The method for extracting hourly diurnal variations from SMILES data was described in S13. Note that the times of SR and SS are 18:00 LT $( \pm 0.3 \mathrm{hr})$ and 06:00 LT $( \pm 0.3 \mathrm{hr})$, respectively, for the region $10^{\circ} \mathrm{S}-10^{\circ} \mathrm{N}$.

For the SD-WACCM output for satellite coincidences (HALOE, SAGE II, and ACE-FTS), the same method was applied as that used for each satellite data set. In contrast, for the full-grid SD-WACCM output diurnal variations as a function of LT were extracted for each latitude and altitude grid point, for each month, as follows. First, 3-hourly diurnal variations in universal time (UT) were calculated at each longitude, latitude, and altitude grid point. Then, along each latitude band, data at the same local time were averaged to obtain diurnal variations as a function of LT; e.g., 00:00 LT data were the average of $\left(00: 00 \mathrm{UT}, 0^{\circ} \mathrm{E}\right)$, (03:00 UT, $\left.315^{\circ} \mathrm{E}\right),\left(06: 00 \mathrm{UT}, 270^{\circ} \mathrm{E}\right),\left(09: 00 \mathrm{UT}, 225^{\circ} \mathrm{E}\right)$, $\left(12: 00 \mathrm{UT}, 180^{\circ} \mathrm{E}\right),\left(15: 00 \mathrm{UT}, 135^{\circ} \mathrm{E}\right),\left(18: 00 \mathrm{UT}, 90^{\circ} \mathrm{E}\right)$, and $\left(21: 00 \mathrm{UT}, 45^{\circ} \mathrm{E}\right)$. Using these data, as for SMILES, the
SSD caused by diurnal variations, that is, the difference between 18:00 and 06:00 LT, was calculated. For SD-WACCM, as was done by $\mathrm{S} 13$, the contributions from vertical transport and photochemistry were estimated by integrating Eq. (1). Diurnal variations of vertical wind $\left(w^{\prime}\right)$ and photochemical generation or loss $\left(S^{\prime}\right)$ were both derived from the full-grid SD-WACCM output.

\section{Results}

\subsection{Annual mean}

Figure 5a shows the annual mean vertical profiles of the SSD in ozone mixing ratio in the region between $10^{\circ} \mathrm{S}$ and $10^{\circ} \mathrm{N}$, using data from the three solar occultation measurements and from SD-WACCM output during each satellite coincidence. We see that HALOE (blue solid curve) and ACE-FTS (green solid curve) agree well with each other for the entire stratosphere; SD-WACCM results at times of satellite coincidence (blue and green dashed curves) are also quantitatively consistent in the stratosphere (below $\sim 55 \mathrm{~km}$ ). In the lower stratosphere, at an altitude of around $25 \mathrm{~km}$, the SR profiles exhibit $0.05-0.1$ ppmv more ozone than the SS profiles. This difference gradually decreases with increasing altitude and reaches zero at about $30 \mathrm{~km}$. In the upper stratosphere, at $40-45 \mathrm{~km}$, the SS profiles exhibit up to 0.2 ppmv more ozone than the $\mathrm{SR}$ profiles. Figure $5 \mathrm{~b}$ shows the ratio of the SSD to the average ozone mixing ratio during the analysis period. The SSD is between -2 and $-3 \%$ at around $20 \mathrm{~km}$ and gradually increases to $5 \%$ at an altitude of $45 \mathrm{~km}$. The SSD near the stratopause is quantitatively consistent with the HALOE result of Brühl et al. (1996), although they only analyzed two latitude bands at around $18^{\circ} \mathrm{N}$ and $18^{\circ} \mathrm{S}$.

SAGE II (red solid curve) shows a similar result to HALOE and ACE-FTS, at least qualitatively, but the SSD in the upper stratosphere is approximately twice as large as those resulting from the other data sets. The SAGE II results are essentially consistent with the results of McLinden et al. (2009) and Kyrölä et al. (2013), although the latter may be partially contaminated by seasonal/interannual ozone variations (see Sect. 3). Considering that the SD-WACCM results at SAGE II measurement locations (red dashed curve) are consistent with those at both HALOE and ACE-FTS measurement locations, we suggest that the anomalous SAGE II values were not due to the differences in the measurement locations/times compared to HALOE or ACE-FTS. Possible causes will be discussed in Sect. 5 .

There is a disagreement in SSD between satellite measurements and SD-WACCM above $55 \mathrm{~km}$ (Fig. 5). This may be due to the difference in diurnal variations between the model and observations, as shown by $\mathrm{S} 13$ for the altitude region between 50 and $60 \mathrm{~km}$. S13 also found that such a difference was attributed to the difference in the lowest altitude of the dominance of mesospheric diurnal variations that shows a 

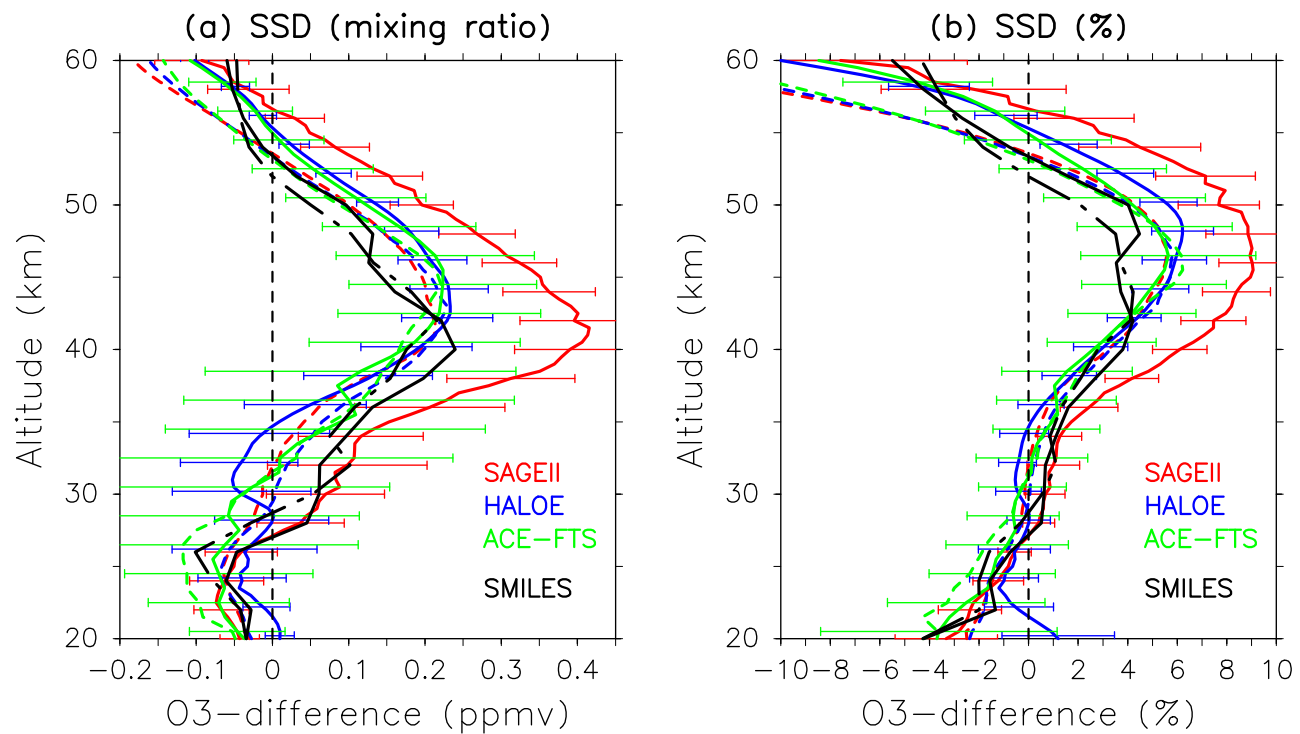

Figure 5. $\mathrm{SSD}_{\text {cor }}$ for $10^{\circ} \mathrm{S}-10^{\circ} \mathrm{N}$ in (a) ozone mixing ratio (ppmv) and (b) SSD ratio to the daily mean (\%), derived from SAGE II (red solid curves), HALOE (blue solid curves), and ACE-FTS (green solid curves). Red, blue, and green dashed curves denote SD-WACCM results at SAGE II, HALOE, and ACE-FTS coincidence, respectively. Black solid curves show the SMILES result (SR and SS are defined by those profiles with a solar zenith angle between $80^{\circ}$ and $100^{\circ}$ ). Black dot-dashed curves show the difference between 18:00 and 06:00 LT, calculated using SMILES data and based on 1-hourly diurnal variations. Horizontal bars for SAGE II, HALOE, and ACE-FTS show 95\% confidential levels in a $t$ test. For the statistical test, the error is defined as the standard deviation for the monthly SSD; this quantity has been propagated to the error in annual mean. Then, the $t$ test has been made with the degrees of freedom being the total numbers of SR-SS pairs for each data set.

marked day-night contrast; i.e., ozone concentration maximizes (minimizes) during the nighttime (daytime). Another possible reason for the disagreement in SSD is that the strong "horizontal" gradient of ozone concentration associated with the rapid ozone changes at SS/SR in the mesosphere was not considered in the retrieval of satellite measurements (Natarajan et al., 2005).

Figure 5 also shows the two SMILES results. One is the SSD deduced from the solar zenith angle (black solid curve), while the other is the difference between 18:00 and 06:00 LT caused by diurnal variations (black dot-dashed curve). We see that the HALOE and ACE-FTS results are strongly supported by the SMILES results, although the SMILES SSD is about $2 \%$ smaller than that based on HALOE and ACEFTS data at an altitude of approximately $45 \mathrm{~km}$. This may be because SMILES observations have only four SR-SS pairs in total whereas the HALOE and ACE-FTS have 86 and 24 pairs, respectively. SD-WACCM results at SMILES locations also exhibit a smaller SSD compared with SDWACCM results at HALOE and ACE-FTS locations (not shown). It should be noted that there is an agreement of the two results derived from the SMILES data. Also, Fig. 6 compares the SSD from SD-WACCM results at HALOE measurement locations (gray solid curve) to that caused by diurnal variations from full-grid SD-WACCM (black solid curve) and again shows a good agreement. These findings indicate that the SSD is predominantly caused by natural di- urnal variations in ozone concentrations (i.e., not by instrumental/retrieval bias).

Based on the finding that the SSD is consistent between satellite measurements (at least HALOE and ACE-FTS) and SD-WACCM, SD-WACCM data are further examined. Figure 7 shows diurnal variations in ozone mixing ratio at $42 \mathrm{~km}$, $32 \mathrm{~km}$, and $26 \mathrm{~km}$, as derived from full-grid SD-WACCM data (black solid curve). The contribution from vertical transport by atmospheric tides (red solid curve) and that from photochemistry (blue solid curve) are also shown (see Eq. (1) and Sect. 3). As shown by S13, the sum of the two processes (black dashed curve) explains almost all characteristics of diurnal variations (black solid curve). At $26 \mathrm{~km}$, ozone levels reach a maximum in the morning and a minimum in the afternoon in the lower stratosphere mainly due to tidal vertical transport, resulting in a negative SSD. At $32 \mathrm{~km}$, ozone levels show a significant diurnal variation during the daytime due to photochemistry but they are almost zero at SR and SS, resulting in almost zero SSD. Chapman mechanism and NOx chemistry are related to the photochemical variations (Pallister and Tuck, 1983; Schanz et al., 2014). At $42 \mathrm{~km}$, ozone levels show a diurnal variation caused by both vertical transport and photochemistry. However, as is the case at $32 \mathrm{~km}$, photochemical processes do not contribute to the SSD significantly. In contrast, the vertical transport generates higher ozone levels in the late afternoon than in the morning; this causes a positive SSD. The vertical transport exhibits only 


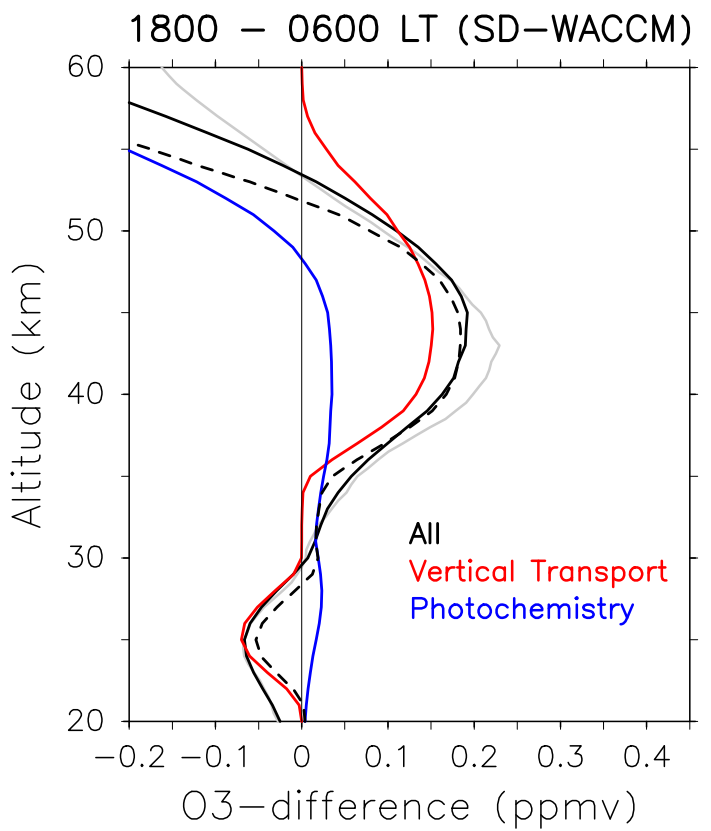

Figure 6. As Fig. 5a but for the difference between 18:00 and 06:00 LT, as deduced from diurnal variations in ozone concentration based on full-grid SD-WACCM between 2008 and 2010. Solid curve is for the diurnal variations, red solid curve is for the contribution from the vertical transport, blue solid curve is for the contribution from photochemical processes, and the dashed solid curve is for the sum of tidal vertical transport and photochemical processes (see Eq. (1) and Sect. 3 for details). Solid gray curve shows the SSD in SD-WACCM data at HALOE measurement locations (the same as blue dashed curve in Fig. 5) for a reference.

small variations at $32 \mathrm{~km}$ because of the small vertical gradient in the background ozone concentration, i.e.,

$\frac{\partial\left[\overline{\mathrm{O}_{3}}\right]}{\partial z} \approx 0$

in Eq. (1) (see Fig. 7d of S13).

Figure 8 shows the amplitude and phase of diurnal migrating tide in vertical wind averaged between $10^{\circ} \mathrm{S}$ and $10^{\circ} \mathrm{N}$, as derived from SD-WACCM data. The amplitude exponentially increases with altitude. The phase basically shows the downward progression, but it is almost constant around $40 \mathrm{~km}$ possibly due to the presence of trapped modes excited by ozone heating (e.g., Sakazaki et al., 2013b). Consequently, the phase of vertical wind is similar in the whole stratosphere; thus, the sign of SSD (i.e., negative at 20-30 km and positive at $35-50 \mathrm{~km}$ ) is determined by that of vertical gradient in the background ozone concentration.

Figure 6 summarizes the contributions from vertical transport and photochemistry (blue curve) to the annual mean SSD profile.As discussed above, the SSD in the tropical stratosphere is mainly caused by vertical transport while the contribution from photochemistry is negligible. Note that a further analysis of SD-WACCM indicated that the photo-
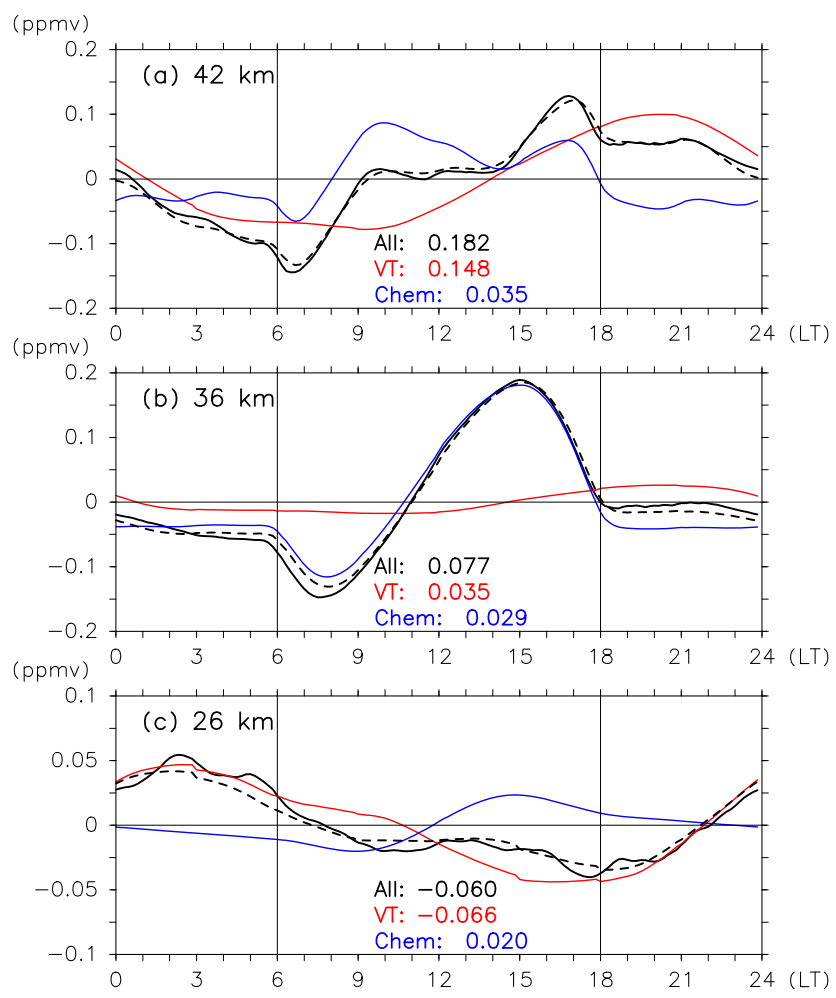

Figure 7. Diurnal variations in ozone mixing ratio averaged over $10^{\circ} \mathrm{S}-10^{\circ} \mathrm{N}$ at altitudes of (a) $42 \mathrm{~km}$, (b) $36 \mathrm{~km}$, and (c) $26 \mathrm{~km}$. Black solid curves are SD-WACCM. Red solid curves show the contribution from tidal vertical transport and blue solid curves show the contribution from photochemical processes (see Eq. (1) and Sect. 3), while black dashed curves show the sum of the two processes. SR and SS are denoted by thin black solid lines at 06:00 LT and 18:00 LT, respectively. The differences between 18:00 and 06:00 LT in ozone concentration (ppmv) from diurnal variations ("All"), tidal vertical transport ("VT"), and photochemical processes ("Chem") are shown in each panel.

chemical variations cause a SSD of $\sim 0.1 \mathrm{ppmv}$ at high latitudes $\left(>40^{\circ}\right)$ where they are not zero at SR and SS (not shown; cf. Schanz et al., 2014). The relationship between the SSD and vertical tidal winds will be further demonstrated in the next section, where we will examine the seasonal variations of the SSD.

\subsection{Seasonal variations}

This section examines seasonal variations in the SSD. It should be emphasized here that by calculating the seasonal variations in SSD using solar occultation measurements we could obtain quasi-observational evidence of seasonal variations in stratospheric vertical tidal winds, which are difficult to observe directly. This section mainly uses HALOE data because the SSD based on the HALOE measurements covers a wider range of months. Figure 9 shows the month-altitude distribution of the SSD from HALOE and SD-WACCM at 


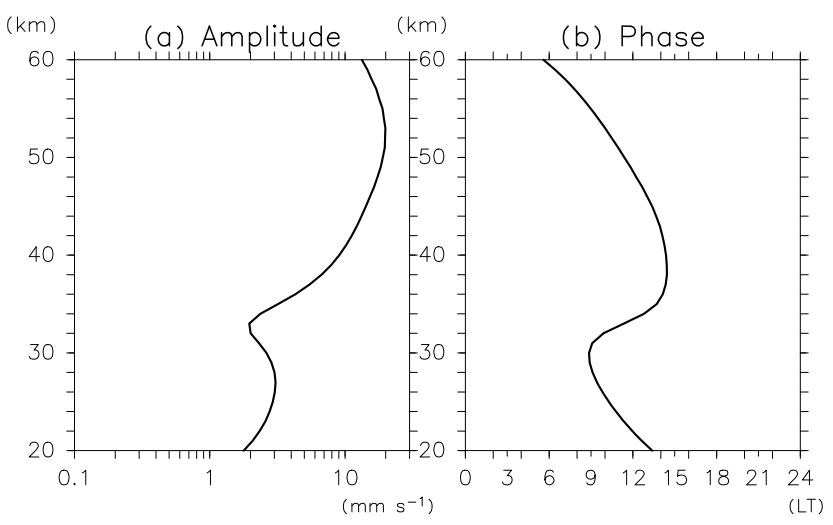

Figure 8. Vertical profiles of (a) amplitude and (b) phase for diurnal migrating tide in vertical wind, averaged between $10^{\circ} \mathrm{S}$ and $10^{\circ} \mathrm{N}$, as derived from SD-WACCM data during the period of 2008-2010.

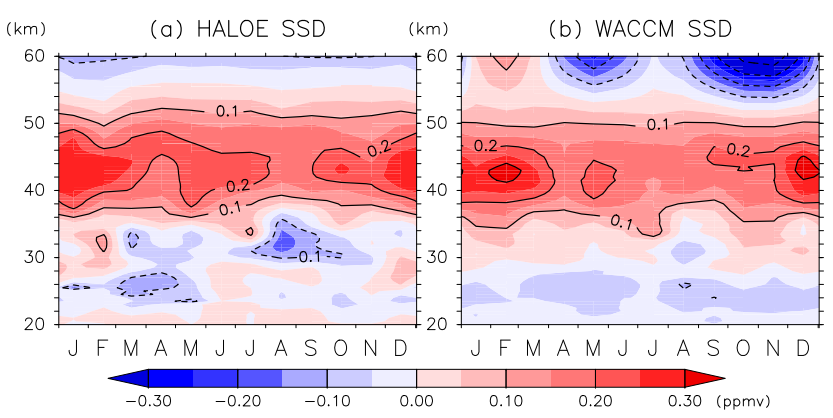

Figure 9. Month-altitude distributions of the SSD for the latitude range $10^{\circ} \mathrm{S}-10^{\circ} \mathrm{N}$, derived from (a) HALOE and (b) SD-WACCM at HALOE measurement locations. Contour intervals are $0.1 \mathrm{ppmv}$.

HALOE locations. In the upper stratosphere at altitudes of $40-50 \mathrm{~km}$, both data sets show that the SSD reaches a maximum during the Northern Hemisphere winter between December and February (0.2-0.3 ppmv; see also Fig. 4). In the lower stratosphere, at $20-30 \mathrm{~km}$, the SSD reaches a minimum twice, in March-April and again in August-October.

These seasonal variations can be confirmed on the basis of other data sets. Figure 10 shows the seasonal variations in the SSD averaged between altitudes of 40 and $45 \mathrm{~km}$ and also between 22 and $28 \mathrm{~km}$, as derived from the three solar occultation measurements as well as the SMILES and SD-WACCM data at satellite measurement locations. In the upper stratosphere (see Fig. 10a), all data are consistent in the sense that the SSD reaches a maximum between December and February. Note that the SSD based on SAGE II data is larger by a constant amount (ca. 0.2 ppmv) for the entire year than that based on the other data sets. In the lower stratosphere (see Fig. 10b) all data (except for those from ACE-FTS) also agree reasonably well, in that the SSD reaches a minimum between March and April while another minimum is discernable between August and November. The disagreement seen for the ACE-FTS data may be caused by the smaller num-
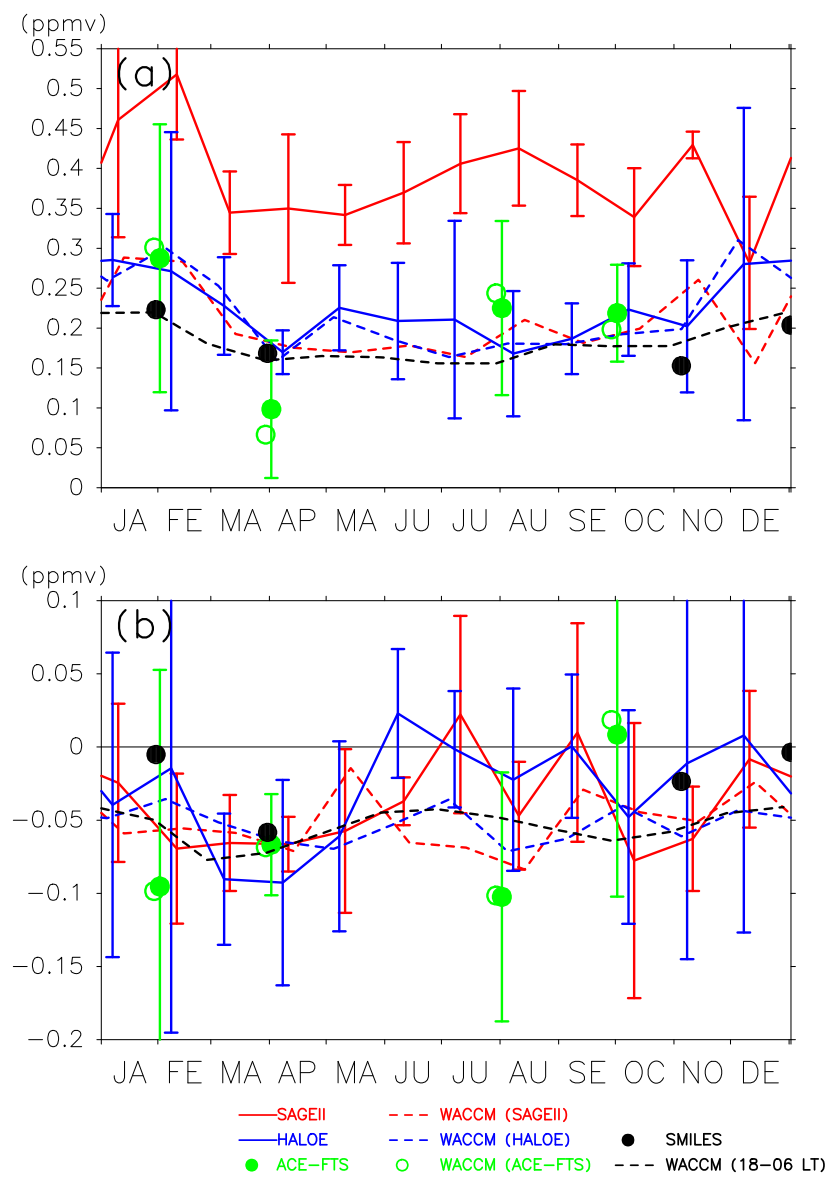

Figure 10. Seasonal variation of $\mathrm{O}_{3} \mathrm{SSD}_{\text {cor }}$ at altitudes of (a) 40 $45 \mathrm{~km}$ and (b) $22-28 \mathrm{~km}$, obtained from (red solid curve) SAGE II, (red dashed curve) SD-WACCM at SAGE II locations, (blue solid curve) HALOE, (blue dashed curve) SD-WACCM at HALOE locations, (green closed circles) ACE-FTS, (green open circles) SD-WACCM at ACE-FTS locations, and (black closed circles) SMILES. The black dashed curve shows the difference in ozone between 18:00 and 06:00 LT, as deduced from diurnal variations in ozone concentration based on full-grid SD-WACCM between 2008 and 2010. Vertical bars for SAGE II, HALOE, and ACE-FTS show $95 \%$ confidential levels with a $t$ test.

ber of SR-SS pairs or because $\mathrm{SSD}_{\text {seas }}$ was estimated using HALOE data rather than ACE-FTS data (see Sect. 3).

Based on the finding that the seasonal dependence of SSD in the SD-WACCM data is consistent with the satellite data, the full-grid SD-WACCM data are further analyzed to interpret the seasonal variations of SSD from the perspective of those of diurnal variations in ozone concentration. Figure 11a shows the month-altitude distribution of the difference in ozone mixing ratio between 18:00 LT (for SS) and 06:00 LT (for SR), i.e., the SSD due to diurnal variations as derived from the full-grid SD-WACCM data (see also the black dashed curve in Fig. 10). The seasonal dependence shown in Fig. 11a agrees well with that in Fig. 9b, both in the upper stratosphere (the positive-SSD region) and in the lower 


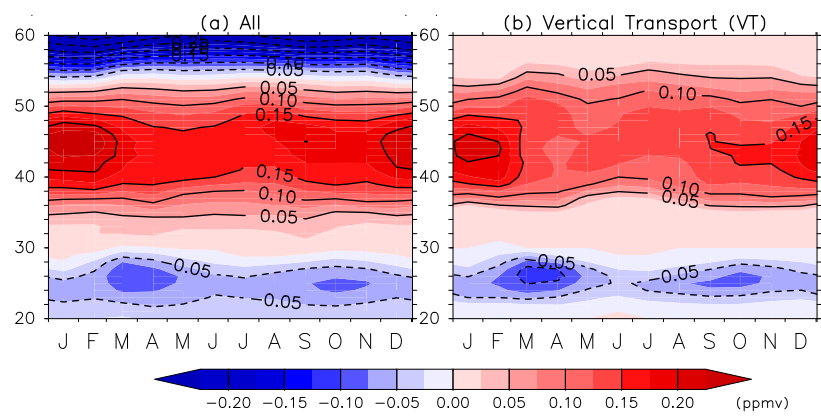

Figure 11. (a) As Fig. 9 but for the difference in ozone mixing ratio between 18:00 and 06:00 LT, deduced from diurnal variations in ozone concentration based on full-grid SD-WACCM during the period 2008-2010. (b) As (a) but for the contribution from tidal vertical transport (see Eq. 1).

stratosphere (the negative-SSD region). We conclude that the seasonal dependence of the SSD is mainly caused by that in the diurnal variations in ozone level. Figure $11 \mathrm{~b}$ shows the seasonal variation of the SSD related to vertical tidal transport only (Eq. 1). Good agreement between Fig. 11a and b again indicates that the SSD can be largely explained by diurnal variations caused by vertical tidal transport. It is also suggested that the seasonal dependence of the SSD is caused by that of the tidal vertical winds.

Although tides are mainly composed of diurnal and semidiurnal components, the former cause the SSD because the semidiurnal cycle does not cause any difference between two measurements taken 12 hours apart (i.e., normal SR and SS at 06:00 and 18:00 LT). Figure 12 shows the tropical month-latitude distributions of the diurnal migrating tide in the vertical winds at 42 and $26 \mathrm{~km}$ derived from the SD-WACCM results. At an altitude of $42 \mathrm{~km}$, the amplitude is greatest during the Northern Hemisphere winter, while a small secondary maximum is discernable in the period August-September between 20 and $10^{\circ} \mathrm{S}$. At $26 \mathrm{~km}$, we see similar double maxima, one in February-March and the other in August-September. The seasonal variations in vertical wind are consistent with those in temperature (e.g., $\mathrm{Wu}$ et al., 1998; Sakazaki et al., 2012). Sakazaki et al. (2013b) attributed the double maxima to the seasonal dependence of the background zonal winds; the meridional advection of the zonal wind momentum peaks twice a year, producing the tidal seasonal variation in the stratosphere. We conclude that the seasonal variation in the vertical tidal wind causes the variation of the vertical transport of ozone (see Fig. 11b) and, consequently, this results in the seasonal variation of the SSD (see Fig. 11a). The secondary maximum in AugustSeptember at an altitude of $42 \mathrm{~km}$, as seen in the vertical wind, does not appear in the SSD, probably because we only analyzed the SSD in the region $10^{\circ} \mathrm{S}-10^{\circ} \mathrm{N}$.
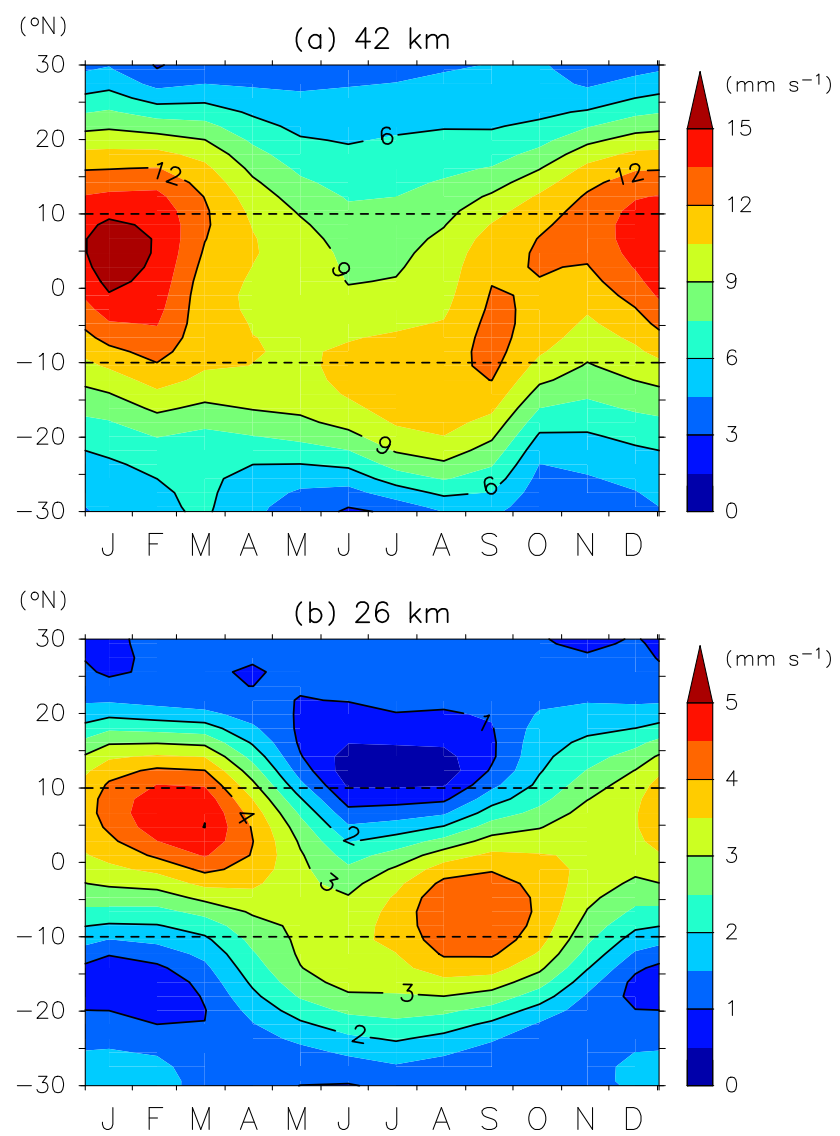

Figure 12. Month-latitude distributions of the amplitude of the diurnal migrating tide in vertical winds at altitudes of (a) $42 \mathrm{~km}$ and (b) $26 \mathrm{~km}$, derived from SD-WACCM data for the period 20082010 .

\section{Discussion and concluding remarks}

We quantified the SSD for the tropical stratosphere based on three different measurements of solar occultation (SAGE II, HALOE, and ACE-FTS) supplemented by data from SMILES measurements and the SD-WACCM model. To quantify the SSD, we addressed the importance of removing the effects of sampling issues on the SSD, particularly contamination by seasonal variations in ozone level. If contamination by seasonal variations in ozone concentration is not removed in advance (i.e., if monthly composites are calculated for $\mathrm{SSD}_{\mathrm{org}}^{i}$, the SSD shows seasonal variations that are contaminated by signals associated with the SAO. These sampling issues should be taken into account when correcting the SSD to create homogenized data sets based on solar occultation measurements.

All data, except for those from SAGE II, indicated that the SSD is up to $+0.2 \mathrm{ppmv}$ in the upper stratosphere at altitudes of $40-45 \mathrm{~km}$ and up to $-0.1 \mathrm{ppmv}$ in the lower stratosphere at around $25 \mathrm{~km}$. SMILES and SD-WACCM results suggested that the SSD is caused by natural diurnal variations in ozone 
concentration, particularly variations related to vertical transport by tidal winds. SAGE II data showed qualitatively similar results, including the seasonal dependence, but the SSD in the upper stratosphere was twice as large as in the other data sets.

The SSD also shows seasonal variations: it reaches a maximum during the Northern Hemisphere winter at an altitude of $42 \mathrm{~km}$ and minima in March-April and August-October near an altitude of $26 \mathrm{~km}$. Analysis of SD-WACCM output showed that the seasonal variation in the SSD follows that of the tidal vertical winds. We believe that we have obtained the first quasi-observational evidence of the tidal vertical wind and its seasonal dependence in the tropical stratosphere. Therefore, we suggest that the ozone SSD is not a bias but a useful proxy for the vertical tidal wind.

Nevertheless, there is an uncertainty about the magnitude of SSD; the SSD from SAGE II data is twice as large as that from the other four data sets. With the analysis of SDWACCM output, this difference is found not due to the difference in measurement locations or times among the data sets. The retrieval procedure in SAGE II has been greatly updated in SAGE II version 7 data (Damadeo et al., 2013). We have so far no clear answer to the difference; there may be several possibilities as discussed in the following.

A SSD could occur if the measurement "altitude" is mistakenly defined at SR and/or SS. However, the observed uncertainty in SSD of $\sim 4 \%$ (the difference in SSD between SAGE II and the others at $42 \mathrm{~km}$ ) corresponds to the uncertainty in altitude of $\sim 400 \mathrm{~m}$ (at $42 \mathrm{~km}$ the ozone mixing ratio changes $1 \%$ per $100 \mathrm{~m}$ in vertical); this seems unrealistic because an uncertainty of defined altitude is considered $20 \mathrm{~m}$ for SAGE II, $100 \mathrm{~m}$ for HALOE, and $150 \mathrm{~m}$ for ACE-FTS.

Another related issue may be the reproducibility of tides in SD-WACCM and reanalyses. Satellite measurements use, more or less, (re)analysis data for the altitude registration and/or the retrieval process. It is found that the amplitude of diurnal tide in SD-WACCM and reanalyses are up to $\sim 50 \%$ smaller in the upper stratosphere compared to data from the Sounding of the Atmosphere using Broadband Emission Radiometry (SABER) measurements (version 2 data) (not shown; see Sakazaki et al., 2012, for the comparison between SABER and reanalyses). This could affect any of the satellite data sets, but a further study is needed for a more quantitative discussion.

Acknowledgements. SAGE II data were provided by the NASA Atmospheric Data Center. HALOE data were provided by GATS, Inc., through their website (http://haloe.gats-inc.com/home/index.php). ACE-FTS data were provided by the ACE Science Operations Centre. The Atmospheric Chemistry Experiment (ACE), also known as SCISAT, is a Canadian-led mission mainly supported by the Canadian Space Agency and the Natural Sciences and Engineering Research Council of Canada. SMILES data were provided by the ISAS/JAXA. Monthly zonal wind data from Singapore were obtained from the Free University of Berlin through its website (http: //www.geo.fu-berlin.de/en/met/ag/strat/produkte/qbo/index.html). SABER version 2 data were provided by GATS, Inc., through their website (ftp://saber.gats-inc.com/custom/Temp_O3/). We thank Koji Imai for his help in working with the ACE-FTS data. We are also grateful to Erkki Kyrölä and Chris Boone for their helpful suggestions and comments. Ellis Remsberg and an anonymous reviewer gave us instructive comments which helped us to improve the manuscript. T. Sakazaki was supported in part by the Japanese Ministry of Education, Culture, Sports, Science and Technology (MEXT) through a grant-in-aid for JSPS Fellows (25483400). T. Sakazaki and M. Suzuki were also supported by the International Space Science Institute, Bern, Switzerland (ISSI Team \#246, Characterizing Diurnal Variations of Ozone for Improving Ozone Trend Estimates, http://www.issbern.ch/teams/ozonetrend/). This study was supported in part by the MEXT through a grant-in-aid (25281006), the ISS Science Project Office of ISAS/JAXA, and the Human Spaceflight Mission Directorate of JAXA. All figures were drawn with the GFD-Dennou library.

Edited by: W. Ward

\section{References}

Beaver, G. M., Gordley, L., and Russell III, J. M.: Halogen Occultation Experiment (HALOE) altitude registration of atmospheric profile measurements: lessons learned and improvements made during the data validation phase, Proc. SPIE 2266, P. Soc. PhotoOpt. Ins., 266-280, doi:10.1117/12.187564, 1994.

Bernath, P. F., McElroy, C. T., Abrams, M. C., Boone, C. D., Butler, M., Camy-Peyret, C., Carleer, M., Clerbaux, C., Coheur, P.-F., Colin, R., DeCola, P., DeMazière, M., Drummond, J. R., Dufour, D., Evans, W. F. J., Fast, H., Fussen, D., Gilbert, K., Jennings, D. E., Llewellyn, E. J., Lowe, R. P., Mahieu, E., McConnell, J. C., McHugh, M., McLeod, S. D., Michaud, R., Midwinter, C., Nassar, R., Nichitiu, F., Nowlan, C., Rinsland, C. P., Rochon, Y. J., Rowlands, N., Semeniuk, K., Simon, P., Skelton, R., Sloan, J. J., Soucy, M.-A., Strong, K., Tremblay, P., Turnbull, D., Walker, K. A., Walkty, I., Wardle, D. A., Wehrle, V., Zander, R., and Zou, J.: Atomspheric Chemistry Experiment (ACE): mission overview, Geophys. Res. Lett., 32, L15S01, doi:10.1029/2005GL022386, 2005.

Boone, C., D., Nassar, R., Walker, K. A., Rochon, Y., McLeod, S. D., Rinsland, C. P., and Bernath, P. F.: retrievals for the atmospheric chemistry experiment Fourier-transform spectrometer, Appl. Optics, 44, 7218-7231, 2005.

Brühl, C., Drayson, S. R., Russell III, J. M., Crutzen, P. J., McInerney, J. M., Purcell, P. N., Claude, H., Gernandt, H., McGee, T. J., McDermid, I. S., and Gunson, M. R.: Halogen Occultation Experiment ozone channel validation, J. Geophys. Res., 101, 10,217-10,240, 1996

Damadeo, R. P., Zawodny, J. M., Thomason, L. W., and Iyer, N.: SAGE version 7.0 algorithm: application to SAGE II, Atmos. Meas. Tech., 6, 3539-3561, doi:10.5194/amt-6-3539-2013, 2013.

Dupuy, E., Walker, K. A., Kar, J., Boone, C. D., McElroy, C. T., Bernath, P. F., Drummond, J. R., Skelton, R., McLeod, S. D., Hughes, R. C., Nowlan, C. R., Dufour, D. G., Zou, J., Nichi- 
tiu, F., Strong, K., Baron, P., Bevilacqua, R. M., Blumenstock, T., Bodeker, G. E., Borsdorff, T., Bourassa, A. E., Bovensmann, H., Boyd, I. S., Bracher, A., Brogniez, C., Burrows, J. P., Catoire, V., Ceccherini, S., Chabrillat, S., Christensen, T., Coffey, M. T., Cortesi, U., Davies, J., De Clercq, C., Degenstein, D. A., De Mazière, M., Demoulin, P., Dodion, J., Firanski, B., Fischer, H., Forbes, G., Froidevaux, L., Fussen, D., Gerard, P., Godin-Beekmann, S., Goutail, F., Granville, J., Griffith, D., Haley, C. S., Hannigan, J. W., Höpfner, M., Jin, J. J., Jones, A., Jones, N. B., Jucks, K., Kagawa, A., Kasai, Y., Kerzenmacher, T. E., Kleinböhl, A., Klekociuk, A. R., Kramer, I., Küllmann, H., Kuttippurath, J., Kyrölä, E., Lambert, J.-C., Livesey, N. J., Llewellyn, E. J., Lloyd, N. D., Mahieu, E., Manney, G. L., Marshall, B. T., McConnell, J. C., McCormick, M. P., McDermid, I. S., McHugh, M., McLinden, C. A., Mellqvist, J., Mizutani, K., Murayama, Y., Murtagh, D. P., Oelhaf, H., Parrish, A., Petelina, S. V., Piccolo, C., Pommereau, J.-P., Randall, C. E., Robert, C., Roth, C., Schneider, M., Senten, C., Steck, T., Strandberg, A., Strawbridge, K. B., Sussmann, R., Swart, D. P. J., Tarasick, D. W., Taylor, J. R., Tétard, C., Thomason, L. W., Thompson, A. M., Tully, M. B., Urban, J., Vanhellemont, F., Vigouroux, C., von Clarmann, T., von der Gathen, P., von Savigny, C., Waters, J. W., Witte, J. C., Wolff, M., and Zawodny, J. M.: Validation of ozone measurements from the Atmospheric Chemistry Experiment (ACE), Atmos. Chem. Phys., 9, 287-343, doi:10.5194/acp-9-287-2009, 2009.

Garcia, R. R., Marsh, D., Kinnison, D. E., Boville, B., and Sassi, F.: simulations of secular trends in the middle atmosphere, 1950-2003, J. Geophys. Res., 112, D09301, doi:10.1029/2006JD007485, 2007.

Gebhardt, C., Rozanov, A., Hommel, R., Weber, M., Bovensmann, H., Burrows, J. P., Degenstein, D., Froidevaux, L., and Thompson, A. M.: Stratospheric ozone trends and variability as seen by SCIAMACHY from 2002 to 2012, Atmos. Chem. Phys., 14, 831-846, doi:10.5194/acp-14-831-2014, 2014.

Huang, F. T., McPeters, R. D., Bhartia, P. K., Mayr, H. G., Frith, S. M., Russell III, J. M., and Mlynczak, M. G.: temperature diurnal variations (migrating tides) in the stratosphere and lower mesosphere based on measurements from SABER on TIMED, J. Geophys. Res., 115, D16121, doi:10.1029/2009JD013698, 2010.

Imai, K., Manago, N., Mitsuda, C., Naito, Y., Nishimoto, E., Sakazaki, T., Fujiwara, M., Froidevaux, L., von Clarmann, T., Stiller, G. P., Murtagh, D. P., Rong, P., Mlynczak, M. G., Walker, K. A., Kinnison, D. E., Akiyoshi, H., Nakamura, T., Miyasaka, T., Nishibori, T., Mizobuchi, S., Kikuchi, K., Ozeki, H., Takahashi, C., Hayashi, H., Sano, T., Suzuki, M., Takayanagi, M., and Shiotani, M.: Validation of ozone data from the Superconducting Submillimeter-Wave Limb-Emission Sounder (SMILES), J. Geophys. Res. Atmos., 118, 5750-5769, doi:10.1002/jgrd.50434, 2013a.

Imai, K., Fujiwara, M., Inai, Y., Manago, N., Suzuki, M., Sano, T., Mitsuda, C., Naito, Y., Hasebe, F., Koide, T., and Shiotani, M.: Comparison of ozone profiles between Superconducting Submillimeter-Wave Limb-Emission Sounder and worldwide ozonesonde measurements, J. Geophys. Res. Atmos., 118, 12755-12765, doi:10.1002/2013JD021094, 2013 b.

Kalnay, E., Kanamitsu, M., Kistler, R., Collins, W., Deaven, D., Gandin, L., Iredell, M., Saha, S., White, G., Woollen, J., Zhu, Y., Chelliah, M., Ebisuzaki, W., W.Higgins, Janowiak, J., Mo, K. C.,
Ropelewski, C., Wang, J., Leetmaa, A., Reynolds, R., Jenne, R., and Joseph, D.: The NCEP/NCAR 40-year reanalysis project, B. Am. Meteorol. Soc., 77, 437-471, 1996.

Kikuchi, K., Nishibori, T., Ochiai, S., Ozeki, H., Irimajiri, Y., Kasai, Y., Koike, M., Manabe, T., Mizukoshi, K., Murayama, Y., Nagahama, T., Sano, T., Sato, R., Seta, M., Takahashi, C. Takayanagi, M., Masuko, H., Inatani, J., Suzuki, M., and Shiotani, M.: Overview and early results of the Superconducting Submillimeter-Wave Limb-Emission Sounder (SMILES), J. Geophys. Res., 115, D23306, doi:10.1029/2010JD014379, 2010. Kinnison, D. E., G. P. Brasseur, S. Walters, R. R. Garcia, F. Sassi, B. A.

Kinnison, D. E., Brasseur, G. P., Walters, S., Garcia, R. R., Sassi, F., Boville, B. A., Marsh, D., Harvey, L., Randall, C., Randel, W., Lamarque, J. F., Emmons, L. K., Hess, P., Orlando, J., Tyndall, J., and Pan, L.: Sensitivity of chemical tracers to meteorological parameters in the MOZART-3 chemical transport model, J. Geophys. Res., 112, D20302, doi:10.1029/2006JD007879, 2007.

Kunz, A., L. L. Pan, P. Konopka, D. E. Kinnision, and Tilmes, S.: Chemical and dynamical discontinuity at the extratropical tropopause based on START08 and WACCM analyses, J. Geophys. Res., 116, D24302, doi:10.1029/2011JD016686, 2011.

Kyrölä, E., Laine, M., Sofieva, V., Tamminen, J., Päivärinta, S.-M., Tukiainen, S., Zawodny, J., and Thomason, L.: Combined SAGE II-GOMOS ozone profile data set for 1984-2011 and trend analysis of the vertical distribution of ozone, Atmos. Chem. Phys., 13, 10645-10658, doi:10.5194/acp-13-10645-2013, 2013.

Lin, S.-J.: A "vertically-Lagrangian" finite-volume dynamical core for global atmospheric models, Mon. Weather Rev., 132, 22932307, 2004.

Marsh, R. M. and Russell III, J. M.: A tidal explanation for the sunrise/sunset anomaly in HALOE low-latitude nitric oxide observations, Geophys. Res. Lett., 27, 3197-3200, 2000.

Marsh, D. R., Mills, M. J., Kinnison, D. E., Lamarque, J.-F., Calvo, N., and Polvani, L. M.: Climate change from 1850 to 2005 simulated in CESM1(WACCM), 73727391, J. Climate, 26, doi:10.1175/JCLI-D-12-00558.1, 2013.

McCormick, M. P.: SAGE II: an overview, Adv. Space Res., 7, 3219-3226, 1987.

McCormick, M. P., Zawodny, J. M., Veiga, R. E., Larsen, J. C., and Wang, P. H.: An overview of SAGE I and II ozone measurements, Planet. Space Sci., 37, 1567-1586, 1989.

McHugh, M., Hervig, M., Magill, B., Thompson, R. E., Remsberg, E., Wrotny, J., and Russell, J.: Improved mesospheric temperature, water vapor and polar mesospheric cloud extinctions from HALO E. Geophys. Res. Lett., 30, 1440, doi:10.1029/2002GL016859, 2003.

McHugh, M., Magill, B., Walker, K. A., Boone, C. D., Bernath, P. F., and Russell, J. M.: Comparison of atmospheric retrievals from ACE and HALOE, Geophys. Res. Lett, 32, 2005.

McLinden, C. A., Tegtmeier, S., and Fioletov, V.: Technical Note: A SAGE-corrected SBUV zonal-mean ozone data set, Atmos. Chem. Phys., 9, 7963-7972, doi:10.5194/acp-9-7963-2009, 2009.

Naujokat, B.: An Update of the Observed Quasi-Biennial Oscillation of the Stratospheric Winds over the Tropics. J. Atmos. Sci., 43, 1873-1877, 1986.

Neale, R. B., Richter, J., Park, S., Lauritzen, P. H., Vavrus, S. J., Rasch, P. J., and Zhang, M.: The Mean Climate of the Commu- 
nity Atmosphere Model (CAM4) in Forced SST and Fully Coupled Experiments, J. Climate, 26, 5150-5168, doi:10.1175/JCLID-12-00236.1, 2013.

Newchurch, M. J., Yang, E.-S., Cunnold, D. M., Reinsel, G. C., Zawodny, J. M., and Russell III, J. M.: Evidence for slowdown in stroatospheric ozone loss: first stage of ozone recovery, J. Geophys. Res., 108, 4507, doi:10.1029/2003JD003471, 2003. Pallister, R. C., and A. F. Tuck, The diurnal variation of ozone in the

Pallister, R. C. and Tuck, A. F.: The diurnal variation of ozone in the upper stratosphere as a test of photochemical theory, Q. J. Roy. Meteor. Soc., 109, 271-284, 1983.

Parrish, A., Boyd, I. S., Nedoluha, G. E., Bhartia, P. K., Frith, S. M., Kramarova, N. A., Connor, B. J., Bodeker, G. E., Froidevaux, L., Shiotani, M., and Sakazaki, T.: Diurnal variations of stratospheric ozone measured by ground-based microwave remote sensing at the Mauna Loa NDACC site: measurement validation and GEOSCCM model comparison, Atmos. Chem. Phys. Discuss., 13, 31855-31890, doi:10.5194/acpd-13-31855-2013, 2013.

Randall, C. E,. Rusch, D. W., Bevilacqua, R. M., Hoppel, K. W., Lumpe, J. D., Shettle, E., Thompson, E., Deaver, L., Zawodny, J., Kyrö, E., Johnson, B., Kelder, H., Dorokhov, V. M., KönigLanglo, G., and Gil, M.: Validation of POAM III ozone: Comparisons with ozonesonde and satellite data, J. Geophys. Res., 108, 4367, doi:10.1029/2002JD002944, 2003.

Randel, W. and Wu, F.: Isolation of the ozone QBO in SAGEII data by singular-value decomposition, J. Atmos. Sci., 53, 2546-2559, 1996.

Ray, E. A. and Holton, J. R.: The tropical semiannual oscillations in temperature and ozone as observed by the MLS, J. Atmos. Sci., 51, 3045-3052, 1994.

Rienecker, M. M., Suarez, M. J., Gelaro, R., Todling, R., Bacmeister, J., Liu, E., Bosilovich, M. G., Schubert, S. D., Takacs, L., Kim, G.-K., Bloom, S., Chen, J., Collins, D., Conaty, A., da Silva, A., Gu, W., Joiner, J., Koster, R. D., Lucchesi, R., Molod, A., Owens, T., Pawson, S., Pegion, P., Redder, C. R., Reichle, R., Robertson, F. R., Ruddick, A. G., Sienkiewicz, M., and Woollen, J.: MERRA: NASA's modern-era retrospective analysis for research and applications, J. Climate, 24, 3624-3648, doi:10.1175/JCLI-D-11-00015.1, 2011.

Remsberg, E., Deaver, L., Wells, J., Lingenfelser, G., Bhatt, P., Gordley, L., Thompson, R., McHugh, M., Russell III, J. M., Keckhut, P., and Schmidlin, F.: An assessment of the quality of Halogen Occultation Experiment temperature profiles in the mesosphere based on comparisons with Rayleigh backscatter lidar and inflatable falling sphere measurements, J. Geophys. Res. Atmos., 107, 4447, doi:10.1029/2001JD001521, 2002.
Russell, III, J. M., Gordley, L. L., Park, J. H., Drayson, S. R., Hesketh, W. D., Cicerone, R. J., Tuck, A. F., Frederick, J. E., Harries, J. E., and Crutzen, P. J.: The halogen occultation experiment, J. Geophys. Res., 98, 10777-10798, 1993.

Sakazaki, T., Fujiwara, M., Zhang, X., Hagan, M. E., and Forbes, J. M.: Diurnal tides from the troposphere to the lower mesosphere as deduced with TIMED/SABER satellite data and six global reanalysis data sets, J. Geophys. Res., 117, D13108, doi:10.1029/2011JD017117, 2012.

Sakazaki, T., Fujiwara, M., Mitsuda, C., Imai, K., Manago, N., Naito, Y., Nakamura, T., Akiyoshi, H., Kinnison, D., Sano, T., Suzuki, M., and Shiotani, M.: Diurnal ozone variations in the stratosphere revealed in observations from the Superconducting Submillimeter-Wave Limb-Emission Sounder (SMILES) on board the International Space Station (ISS), J. Geophys. Res. Atmos., 118, 2991-3006, doi:10.1002/jgrd.50220, 2013a.

Sakazaki, T., Fujiwara, M., and Zhang, X.: Interpretation of the vertical structure and seasonal variation of the diurnal migrating tide from the troposphere to the lower mesosphere, J. Atmos. Sol.Terr. Phys., 105-106, 66-80, 2013b.

Schanz, A., Hocke, K., and Kämpfer, N.: Daily ozone cycle in the stratosphere: global, regional and seasonal behaviour modelled with the Whole Atmosphere Community Climate Model, Atmos. Chem. Phys. Discuss., 14, 5561-5609, doi:10.5194/acpd14-5561-2014, 2014.

Shiotani, M. and Hasebe, F.: Stratospheric ozone variations in the equatorial region as seen in Stratospheric Aerosol and Gas Experiment data, J. Geophys. Res., 99, 14575-14584, 1994.

Wang, H. J., Cunnold, D. M., and Bao, X.: A critical analysis of Stratospheric Aerosol and Gas Experiment ozone trends, J. Geophys. Res., 101, 12495-12514, 1996.

Waymark, C., Walker, K., Boone, C., and Bernath, P.: ACE-FTS version 3.0 data set: Validation and data processing update, Ann. Geophys.-Italy, 56, doi:10.4401/ag-6339, 2013.

World Meteorological Organization (WMO): Scientific assessment of ozone depletion: 2010, Report 52, Global Ozone Research and Monitoring Project, Geneva, 2011.

Wu, D. L., McLandress, C., Read, W. G., Waters, J. W., and Froidevaux, L.: Equatorial diurnal variations observed in UARS Microwave Limb Sounder temperature during 1991-1994 and simulated by the Canadian Middle Atmosphere Model, J. Geophys. Res., 103, 8909-8917, 1998.

Zeng, Z., Randel, W., Sokolovskiy, S., Deser, C., Kuo, Y.-H., Hagan, M., Du, J., and Ward, W.: Detection of migrating diurnal tide in the tropical upper troposphere and lower stratosphere using the Challenging Minisatellite Payload radio occultation data, J. Geophys. Res., 113, D03102, doi:10.1029/2007JD008725, 2008. 